\title{
MEDIUM CONSTITUENTS AS AFFECTING THE GROWTH OF Cordyline terminalis CV. ATOOM IN VITRO: \\ b- EFFECT OF AMINO ACIDS AND VITAMINS OF THE MEDIUM.
}

Awad, A. E. '; A. K. Dawah'; H. A. Emara² and M. S. El-Shaier ${ }^{2}$

1- Horticulture Dep., Fac. of Agriculture, Zagazig Univ. Egypt.

2- Plant Biotechnology Dep., Inst. of Genetic Engineering and Biotechnology, Minufiya Univ. Egypt.

\section{ABSTRACT}

In vitro-derived and sterilized shoots of Cordyline terminalis were used as explants in this study. In order to investigate the effect of some amino acids and vitamins (as medium constituents) on the growth of cordyline in vitro, a recommended medium by Awad et al, (2008a) was used in all experiments. That medium contained $60 \mathrm{~g} / \mathrm{L}$ banana pulp, $1 / 2 \mathrm{MS}, 30 \mathrm{~g} / \mathrm{L}$ sucrose and $2 \mathrm{~g} / \mathrm{L}$ gelrite. As for the effect of amino acids on shoot number/explant, results indicate that sporadic responses were observed with the used treatments, but the addition of arginine at 25 or $50 \mathrm{mg} / \mathrm{L}$ in the recommended medium replacing glycine significantly increased shoot number/explant in all records (three records) compared to the other treatments. However, Serine at $100 \mathrm{mg} / \mathrm{L}$ significantly showed a similar high number of shoots in all three records. In that concern, glycine (at $2 \mathrm{mg} / \mathrm{L}$ as in $\mathrm{MS}$ ) showed lower response in the third record (after 4 months). Some sporadic treatments of amino acids surpassed glycine \{as in MS medium $(2 \mathrm{mg} / \mathrm{L})\}$ in enhancement the colour intensity of cultures. However, that significant increase in colour intensity was only observed during all records (three records) with glutamine at $100 \mathrm{mg} / \mathrm{L}$ and serine at $25 \mathrm{mg} / \mathrm{L}$. Although, glycine $(2 \mathrm{mg} / \mathrm{L})$ observed a significant increase in the growth vigor in the third record only, but some other treatments showed the same high response in all records such as $100 \mathrm{mg} / \mathrm{L}$ glutamine and asparagine at 50 or $100 \mathrm{mg} / \mathrm{L}$. Concerning the vitamins when examined each alone, medium free of vitamins (control) observed significant increase in shoot number/explant of cordyline compared to the medium contained thiamine at normal level as in MS $(0.1 \mathrm{mg} / \mathrm{L})$ or higher level $(0.5 \mathrm{mg} / \mathrm{L})$. Using pyridoxine alone at lower level $0.1 \mathrm{mg} / \mathrm{L}$ ), than that used in MS medium $(0.5 \mathrm{mg} / \mathrm{L})$, showed significant high response in shoot formation especially at the third record (after 4 months from culturing). In the final record ( $3^{\text {rd }}$ record) results show that nicotinic acid at $(0.10 \mathrm{mg} / \mathrm{L})$ showed a significant increase in shoot number when compared to the higher one $(0.50 \mathrm{mg} / \mathrm{L}$ as in MS) and the control (free of nicotinic acid). It was clear that the presence of any of those vitamin alone at 0.1 or $0.5 \mathrm{mg} / \mathrm{L}$ was effective in enhancement both colour intensity and growth vigor of cultures compared to control medium.

Combining more than one vitamin in the medium indicated that, although different combinations illustrated positive responses in all measured parameters (shoot number, colour intensity and growth vigor) but using any of those vitamins alone at $0.1 \mathrm{mg} / \mathrm{L}$ proved to be sufficient in increasing the shoot number and 0.1 or $0.5 \mathrm{mg} / \mathrm{L}$ enhanced both of colour intensity and growth vigor.

\section{INTRODUCTION}

Cordyline teminalis, Family: Liliaceae is an evergreen tropical perennial shrub with terminal tufts of elongated leaves, mostly grown in tropical southeastern Asia, Australia, Hawaii and Bangladesh. It is known as 
Awad, A. E. et al.

Agnishwar in Bangladesh and traditionally used for the treatment of pain and traumatic injury. Leaves are used in inflammation and urinary infection. A thymidine like substances with antiproliferative activity was also isolated from Cordyline terminalis. Moreover, Cordyline terminalis is considered as one of the most common valuable ornamental plant because it combines the advantages of being adapted to grow in-and out door, and features special combination of colours. Plants synthesis vitamins and amino acids endogenously and these are used as catalysts in various metabolic processes. When plant cells and tissue are grown in vitro, some essential vitamins and amino acids are synthesized but only in suboptimal quantitites. Hence it is necessary to supplement the medium with required vitamins and amino acids to achieve the best growth of the tissue (Razdan, 1993). The objective of this study was to investigate the effect of some vitamins (at different concentrations) of the nutrient medium on the growth of cordyline in vitro, and examination the using of various concentrations of some different amino acids in the medium to replace glycine.

\section{MATERIALS AND METHODS}

This work was carried out in the Tissue Culture Laboratory, Genetic Engineering and Biotechnology Research Institute, Minufyia University, Sadat City, during the years of $2003-$ T2006.

Source of explants: this study.

In vitro grown shoots of Cordyline terminalis were used as explants in

\section{Culture medium}

The medium used in all experiments of this study was recommended by Awad et al, (2008a) as a result of the first part of this work. That medium consisted of $60 \mathrm{~g} / \mathrm{L}$ banana pulp, $1 / 2 \mathrm{MS}$ medium, $1 \mathrm{mg} / \mathrm{L} \mathrm{BA}, 30 \mathrm{~g} / \mathrm{L}$ sucrose and $2 \mathrm{~g} / \mathrm{L}$ gelrite. This medium was used to study the effect of different amino acids and vitamins on the growth of cordyline in vitro.

\section{This study was designed as following:}

(1): Examination of different types of amino acids at different concentrations (in the recommended medium by Awad et al, 2008a) on the growth of cordyline terminals in vitro.

Fifteen treatments were carried out, using the chosen medium $(60 \mathrm{~g} / \mathrm{L}$ banana $+1 / 2 \mathrm{MS}$ ) as following:

1- Control (medium free of glycine).

2- Adding glycine at normal concentration as in MS (2 mg/ L).

3- The treatments from 3 to 15 contained some other amino acids (to replace glycine), glutamine, asparagine, arginine and serine. These amino acids were added to the media each alone at the concentrations 25, 50, 100 $\mathrm{mg} / \mathrm{L}$, and combinations between them at one concentration of each $(25$ $\mathrm{mg} / \mathrm{L})$.

Each treatment consists of 10 replicates (Jars). Each Jar contained 30 $\mathrm{ml}$ of medium with one explant. Cultures were incubated for one month in growth room. Parameters were taken as, number of shoots, color intensity, growth vigor and number of roots. 
These cultures were recultured and incubated for another month under the same conditions. The same parameters were taken again.

After second record the plants were left to grow in Jars without reculutring for two months, and then the previous records were taken.

(2): Examination of different concentrations of some vitamins in the chosen medium (60g/ L banana $+\frac{1}{2} \mathrm{MS}$ ) on the growth of Cordyline terminals in vitro.

This medium was used to carry out different experiments, including different treatments to examine various concentrations $(0.0,0.1,0.5 \mathrm{mg} / \mathrm{L})$ of thiamine, pyridoxine and Nicotinic acid each alone and in combinations.

Each treatment consists of 10 replicates (Jars), and each jar contained $30 \mathrm{ml}$ of medium with one explant. Cultures were incubated for one month under the same culture conditions in growth room. Parameters were taken as, number of shoots, colour intensity, growth vigor and number of roots. These cultures were recultured and incubated for another monthin the growth room. The same parameters were taken again.

After second record the plants were left to grow in the Jars without reculturing for two months, and then the previous records were taken.

Incubation conditions: Cultures of all experiments during this study were incubated under the temperature of $24^{\circ} \mathrm{C}$ day and night. Light was provided by fluorescent tubes giving an intensity of 1500 lux at the level of culture jars for 16 hours per day.

All experiments were repeated twice and the represented data were averages. Results of these experiments were analyzed by analysis of variance (ANOVA) according to Gomez and Gomez (1984).

\section{RESULTS AND DISCUSSION}

\section{1- Effect of some amino acid on the growth of Cordyline terminalis explants in vitro. \\ a- Number of shoots}

Data in Table (1) clearly indicate that sporadic responses were observed, but, the addition of arginine at 25 or $50 \mathrm{mg} / \mathrm{L}$ in the chosen medium replacing glycine significantly increased shoot number/Jar in all records (three records) compared to the other treatments (Fig. 1). However, serine at $100 \mathrm{mg} / \mathrm{L}$ significantly showed a similar high number of shoots in the three records. Interestingly, the free of amino acids (control) significantly observed similar positive result in shoot number as the same of arginine and serine. In that concern, Ghosh and Sen (1994) reported that the development of shoots from callus of Asparagus plumosus was on medium containing benzyladenine, L-arginine and level of NAA. Alka (2003) recorded that bulbils of Dioscorea bulbifera could be used for direct plantlet differentiation as well as bulbil differentiation on MS +10.0 micro M IAA +20.0 micro $M$ Kinetin (Kin) $+30 \mathrm{mg} / \mathrm{L} \mathrm{Asp.} \mathrm{(asparagine)}+30 \mathrm{mg} / \mathrm{L} \mathrm{Arg}$. (arginine ) $+30 \mathrm{mg} / \mathrm{L}$ Glu (glutamine ) $+10 \mathrm{mg} / \mathrm{L} \mathrm{Ad}$. ( adenime ) $+10 \mathrm{mg} / \mathrm{L}$ Cys hyd (Cysteine hydrochloride ). 
Awad, A. E. et al.

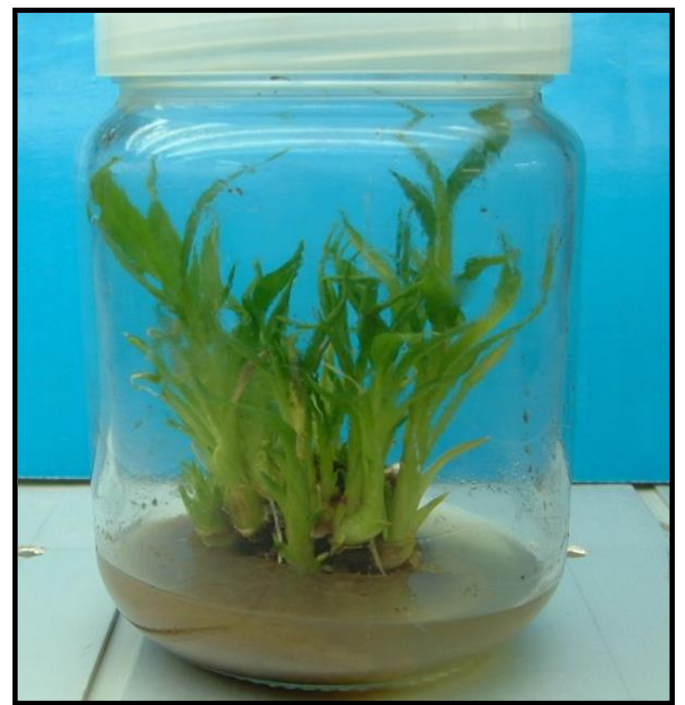

Fig, (1): Cordyline plantlets grown in the recommended medium contained 1/2 MS $+60 \mathrm{~g} / \mathrm{L}$ banana pulp and arginine at 50 $\mathrm{mg} / \mathrm{L}$.

\section{b- Colour intensity}

Data in Table (1) explain that some amino acids surpassed glycine \{as in MS medium (2mg/ L)\} in enhancement the colour intensity, as glutamine at $100 \mathrm{mg} / \mathrm{L}$ showed the significant increase in colour intensity in the three records. However, asparagine at 50 and $100 \mathrm{mg} / \mathrm{L}$ observed the same significant increase in that concern in the $1^{\text {st }}$ and $3^{\text {rd }}$ records. The significant increase was recorded with the following treatments, serine at 25 $\mathrm{mg} / \mathrm{L}$ in the all records and at 50 or $100 \mathrm{mg} / \mathrm{L}$ in the third record only, and arginine at 25 or $50 \mathrm{mg} / \mathrm{L}$ in the third record.

All other treatments including the control (MS without amino acids) showed the lower records.

\section{C- Growth vigor}

Data in Table (1) indicate that glutamine $\left(50 \mathrm{mg} / \mathrm{L}\right.$ in $1^{\text {st }}$ record and $100 \mathrm{mg} / \mathrm{L}$ in all records) and asparagine (50 and $100 \mathrm{mg} / \mathrm{L}$ in all records) significantly observed the highest values of growth vigor. Moreover, arginine at $25 \mathrm{mg} / \mathrm{L}$ significantly showed the value. However, the same significant increase was recorded with glycine treatment in the third record. All other treatments including the control (MS without amino acids) showed the lower records compared to the above mentioned treatments.

These results are in a harmony with that reported by Kamada and Harada (1979) mentioned that the effects of various L-amino acids on in vitro organogenesis were also investigated using $\mathrm{KnO} 3$ as the principal source of nitrogen in the medium, bud formation was considerably stimulated by alanine and asparagine and slightly by glutamic acid in a medium containing both NAA and BA (in which bud formation of Torenia fournieri was easily 
induced). Alka (2003) recorded that bulbils of Dioscorea bulbifera could be used for direct plantlet differentiation as well as bulbil differentiation on MS + 10.0 micro M IAA + 20.0 micro M Kin $+30 \mathrm{mg} / \mathrm{L}$ aspargine $+30 \mathrm{mg} / \mathrm{L}$ Arginine $+30 \mathrm{mg} / \mathrm{L}$ Glutamine $+10 \mathrm{mg} / \mathrm{L}$ adenine $+10 \mathrm{mg} / \mathrm{L}$ cysteine hydrochloride. Thiruvengadam et al, (2006) recorded that full strength MS medium containing $50 \mathrm{mg} / \mathrm{L}$ PVP and $40 \mathrm{mg} / \mathrm{L}$ glutamine was effective to achieve a high frequency of somatic embryo induction, maturation and further development of an embryogenesis suspension culture of bitter melon.

Table (1): Effect of different amino acids at different concentrations [in the chosen medium $(60 \mathrm{~g} / \mathrm{L}$ banana $+1 / 2 \mathrm{MS})$ ] on shoot number, colour intensity and growth vigor of Cordyline terminalis in vitro.

\begin{tabular}{|c|c|c|c|c|c|c|c|c|c|c|}
\hline \multirow{3}{*}{\multicolumn{2}{|c|}{\begin{tabular}{|c|} 
Characters \\
Amino acids $\mathrm{mg} / \mathrm{L}$
\end{tabular}}} & \multirow{2}{*}{\multicolumn{3}{|c|}{$\begin{array}{c}\text { Shoot number } \\
\text { Records }\end{array}$}} & \multirow{2}{*}{\multicolumn{3}{|c|}{$\begin{array}{c}\text { Colour intensity } \\
\text { Records }\end{array}$}} & \multirow{2}{*}{\multicolumn{3}{|c|}{$\begin{array}{c}\text { Growth vigor } \\
\text { Records }\end{array}$}} \\
\hline & & & & & & & & & & \\
\hline & & 1st & 2nd & 3rd & 1st & 2nd & 3rd & 1st & 2nd & 3rd \\
\hline \multicolumn{2}{|c|}{$\begin{array}{l}\text { Control } \\
\text { (without Glycine) }\end{array}$} & $\begin{array}{l}a b c \\
4.20\end{array}$ & $\begin{array}{c}\text { abcde } \\
5.80\end{array}$ & $\begin{array}{l}\text { efg } \\
9.20\end{array}$ & $\begin{array}{c}\text { de } \\
2.80\end{array}$ & $\begin{array}{l}\text { efg } \\
3.00\end{array}$ & c 3.20 & $\begin{array}{c}e \\
2.20\end{array}$ & $\begin{array}{c}\mathrm{h} \\
2.40\end{array}$ & $\begin{array}{c}e \\
2.40\end{array}$ \\
\hline \multicolumn{2}{|l|}{$\begin{array}{l}\text { Glycine } \\
\text { as in MS }\end{array}$} & $\begin{array}{c}a b \\
4.40\end{array}$ & $\begin{array}{l}\text { abcd } \\
6.20\end{array}$ & $\begin{array}{c}\mathrm{bc} \\
16.20\end{array}$ & $\begin{array}{l}\text { bcd } \\
3.20\end{array}$ & $\begin{array}{l}\text { cde } \\
3.40\end{array}$ & $\begin{array}{c}b c \\
3.40\end{array}$ & $\begin{array}{c}b c \\
3.40\end{array}$ & $\begin{array}{l}\text { def } \\
3.40\end{array}$ & $\begin{array}{c}a b \\
3.80\end{array}$ \\
\hline \multirow{3}{*}{ Glutamine } & 25 & $\begin{array}{l}\text { abcd } \\
4.00\end{array}$ & $\begin{array}{l}\text { abcde } \\
5.60\end{array}$ & $\begin{array}{l}\text { def } \\
9.80\end{array}$ & $\begin{array}{c}d e \\
2.80\end{array}$ & $\begin{array}{l}\mathrm{bcd} \\
3.60\end{array}$ & $\begin{array}{c}c \\
3.20\end{array}$ & $\begin{array}{l}\text { cde } \\
2.80\end{array}$ & $\begin{array}{l}\text { defg } \\
3.20\end{array}$ & $\begin{array}{c}\mathrm{de} \\
2.60\end{array}$ \\
\hline & 50 & $\begin{array}{l}\text { bcde } \\
2.20\end{array}$ & $\begin{array}{c}\mathrm{De} \\
4.00\end{array}$ & $\begin{array}{l}f g \\
8.40\end{array}$ & $\begin{array}{l}a b c \\
3.40\end{array}$ & $\begin{array}{l}\text { bcd } \\
3.60\end{array}$ & $\begin{array}{c}c \\
3.20\end{array}$ & $\begin{array}{c}\mathrm{a} \\
4.20\end{array}$ & $\begin{array}{l}\text { bcd } \\
3.80\end{array}$ & $\begin{array}{l}\text { cde } \\
2.80\end{array}$ \\
\hline & 100 & $\begin{array}{c}\text { abcde } \\
3.00\end{array}$ & $\begin{array}{l}\text { cde } \\
4.60\end{array}$ & $\begin{array}{l}\mathrm{Kg} \\
7.40\end{array}$ & $\begin{array}{c}\mathrm{a} \\
3.80\end{array}$ & $\begin{array}{c}\mathrm{a} \\
4.40\end{array}$ & $\begin{array}{c}a b \\
3.80\end{array}$ & $\begin{array}{c}\mathrm{a} \\
4.40\end{array}$ & $\begin{array}{c}a b \\
4.40\end{array}$ & $\begin{array}{c}a b \\
3.80\end{array}$ \\
\hline \multirow{3}{*}{ Asparagine } & 25 & $\begin{array}{l}\text { cde } \\
2.00\end{array}$ & $\begin{array}{l}\mathrm{de} \\
3.80\end{array}$ & $\begin{array}{c}\mathrm{fg} \\
8.40\end{array}$ & $\begin{array}{l}\text { bcd } \\
3.20\end{array}$ & $\begin{array}{l}\text { cde } \\
3.40\end{array}$ & $\begin{array}{c}b c \\
3.40\end{array}$ & $\begin{array}{l}\text { cde } \\
2.80\end{array}$ & $\begin{array}{l}\text { fgh } \\
2.80\end{array}$ & $\begin{array}{c}\mathrm{de} \\
2.60\end{array}$ \\
\hline & 50 & $\begin{array}{l}\text { bcde } \\
2.40\end{array}$ & $\begin{array}{c}\text { de } \\
3.80\end{array}$ & $\begin{array}{c}g \\
5.80\end{array}$ & $\begin{array}{c}\mathrm{a} \\
3.80\end{array}$ & $\begin{array}{c}\mathrm{bc} \\
3.80\end{array}$ & $\begin{array}{c}a b \\
3.80\end{array}$ & $\begin{array}{c}a \\
4.60\end{array}$ & $\begin{array}{l}a b c \\
4.20\end{array}$ & $\begin{array}{c}\mathrm{a} \\
4.00\end{array}$ \\
\hline & 100 & $\begin{array}{c}\text { abcde } \\
3.20\end{array}$ & $\begin{array}{l}\text { bcde } \\
4.80 \\
\end{array}$ & $\begin{array}{c}\mathrm{fg} \\
6.60\end{array}$ & $\begin{array}{c}a b \\
3.60\end{array}$ & $\begin{array}{l}\text { bcd } \\
3.60\end{array}$ & $\begin{array}{c}a b \\
3.80\end{array}$ & $\begin{array}{c}\mathrm{a} \\
4.20 \\
\end{array}$ & $\begin{array}{c}\mathrm{a} \\
4.60 \\
\end{array}$ & $\begin{array}{c}a \\
4.00 \\
\end{array}$ \\
\hline \multirow{3}{*}{ Serine } & 25 & $\begin{array}{c}\mathrm{De} \\
1.80\end{array}$ & $\begin{array}{c}\mathrm{e} \\
3.60\end{array}$ & $\begin{array}{c}g \\
5.40\end{array}$ & $\begin{array}{c}a b \\
3.60\end{array}$ & $\begin{array}{c}\mathrm{ab} \\
4.00\end{array}$ & $\begin{array}{c}\mathrm{a} \\
4.00\end{array}$ & $\begin{array}{l}\text { cde } \\
3.20\end{array}$ & $\begin{array}{l}\text { bcd } \\
3.80\end{array}$ & $\begin{array}{c}a b \\
3.80\end{array}$ \\
\hline & 50 & $\begin{array}{c}\text { abcde } \\
3.40\end{array}$ & $\begin{array}{l}a b c \\
7.00\end{array}$ & $\begin{array}{c}c d \\
13.20\end{array}$ & $\begin{array}{c}\text { de } \\
2.80\end{array}$ & $\begin{array}{c}\text { efg } \\
3.00\end{array}$ & $\begin{array}{c}\mathrm{a} \\
4.00\end{array}$ & $\begin{array}{c}b c \\
3.40\end{array}$ & $\begin{array}{l}\text { defg } \\
3.20\end{array}$ & $\begin{array}{l}a b c \\
3.40\end{array}$ \\
\hline & 100 & $\begin{array}{c}\text { abcde } \\
3.80\end{array}$ & $\begin{array}{c}\mathrm{ab} \\
7.20\end{array}$ & $\begin{array}{c}a \\
22.60\end{array}$ & $\begin{array}{l}\text { cde } \\
3.00\end{array}$ & $\begin{array}{c}\text { def } \\
3.20 \\
\end{array}$ & $\begin{array}{c}\mathrm{a} \\
4.00 \\
\end{array}$ & $\begin{array}{c}\mathrm{cd} \\
3.20\end{array}$ & $\begin{array}{l}\text { defg } \\
3.20 \\
\end{array}$ & $\begin{array}{c}a b \\
3.60\end{array}$ \\
\hline \multirow{3}{*}{ Arginine } & 25 & $\begin{array}{c}a \\
5.00\end{array}$ & $\begin{array}{c}\mathrm{a} \\
7.80\end{array}$ & $\begin{array}{c}a \\
21.00\end{array}$ & $\begin{array}{l}\text { cde } \\
3.00\end{array}$ & $\begin{array}{l}\text { bcd } \\
3.60\end{array}$ & $\begin{array}{c}\mathrm{a} \\
4.00\end{array}$ & $\begin{array}{c}\mathrm{ab} \\
4.00\end{array}$ & $\begin{array}{c}\text { cde } \\
3.60\end{array}$ & $\begin{array}{c}\mathrm{a} \\
4.00 \\
\end{array}$ \\
\hline & 50 & $\begin{array}{c}\text { abcde } \\
3.60\end{array}$ & $\begin{array}{c}\mathrm{a} \\
7.60\end{array}$ & $\begin{array}{c}a b \\
19.80\end{array}$ & $\begin{array}{l}\text { cde } \\
3.00\end{array}$ & $\begin{array}{c}\mathrm{g} \\
2.60\end{array}$ & $\begin{array}{c}\mathrm{a} \\
4.00\end{array}$ & $\begin{array}{c}\mathrm{cd} \\
3.20\end{array}$ & $\begin{array}{l}\text { efgh } \\
3.00\end{array}$ & $\begin{array}{l}\text { bcd } \\
3.20\end{array}$ \\
\hline & 100 & $\begin{array}{c}\mathrm{e} \\
1.60\end{array}$ & $\begin{array}{c}d e \\
4.20\end{array}$ & $\begin{array}{c}\text { cde } \\
12.60\end{array}$ & $\begin{array}{c}e \\
2.60\end{array}$ & $\begin{array}{c}f g \\
2.80\end{array}$ & c 3.20 & $\begin{array}{c}c \text { cd } \\
3.00\end{array}$ & $\begin{array}{c}\text { fgh } \\
2.80\end{array}$ & $\begin{array}{c}\mathrm{de} \\
2.60\end{array}$ \\
\hline \multicolumn{2}{|c|}{$\begin{array}{l}\text { Glutamine 25+Asp } \\
25+\text { Serine } 25+ \\
\text { Arginine } 25\end{array}$} & $\begin{array}{c}\text { abcde } \\
3.20\end{array}$ & $\begin{array}{l}a b c \\
6.80\end{array}$ & $\begin{array}{c}\text { C } \\
15.40\end{array}$ & $\begin{array}{c}\mathrm{e} \\
2.60\end{array}$ & $\begin{array}{c}g \\
2.60\end{array}$ & $\begin{array}{c}a b c \\
3.60\end{array}$ & $\begin{array}{c}\text { de } \\
2.60\end{array}$ & $\begin{array}{c}\text { gh } \\
2.60\end{array}$ & $\begin{array}{l}\text { cde } \\
2.80\end{array}$ \\
\hline
\end{tabular}


Awad, A. E. et al.

2- Effect of different vitamins (thiamine, pyridoxine, and nicotinic acid) at different concentrations in the chosen medium $(60 \mathrm{~g} / \mathrm{L}$ banana + $1 / 2 \mathrm{Ms}$ ) on the growth of Cordyline terminals in vitro.

A- The effect on shoot number/explant

A1- Effect of single vitamin on number of shoot:

Regarding thiamine, data presented in Table (2) indicate that the higher thiamine concentration $(0.5 \mathrm{mg} / \mathrm{L})$ and the normal level as in MS $(0.10$ $\mathrm{mg} / \mathrm{L}$ ) resulted in significant increase in shoot number in the three records compared to the treatment devoid of vitamin in the $1^{\text {st }}$ and $2^{\text {nd }}$ records. However, the $3^{\text {rd }}$ record of that medium free of vitamins showed the same high response as mentioned above. These results agreed with that reported by Le (1980) who stated that adventitious buds were obtained after 8 weeks when Aeschynanthus hildebrandii leaf fragments were cultured on Murashige and Skoog basal medium supplemented by $0.1 \mathrm{mg} / \mathrm{L}$ thiamine, $0.5 \mathrm{mg} / \mathrm{L}$ pyridoxin, $0.5 \mathrm{mg} / \mathrm{L}$ nicotinic acid, $100 \mathrm{mg} / \mathrm{L}$ myo-inositol, $0.01 \mathrm{mg} / \mathrm{L}$ alpha NAA, $0.1 \mathrm{mg} / \mathrm{L}$ IBA, $30 \mathrm{~g} / \mathrm{L}$ sucrose and $0.8 \%$ agar. Khosh et al, (1984) mentioned that optimum shoot proliferation of myrtle was obtained on medium containing half strength. Murashige and Skoog plus (in $\mathrm{mg} / \mathrm{L}$ ) nicotinic acid 0.5 , pyridoxine $\mathrm{HCL}, 0.5$, thiamine $\mathrm{HCL} 0.1$, glycine 2.0 , inosital 100, BA 1.5, and NAA 0.1. Sharma et al., (1984) found that the best results were obtained when explants of date palm were cultured on modified MS medium containing activated Charcoal (0.3\%), $\mathrm{Na} \mathrm{H}_{2} \mathrm{Po}_{4}(170 \mathrm{mg} / \mathrm{L}), \mathrm{KH}_{2}$ $\mathrm{Po}_{4}(200 \mathrm{mg} / \mathrm{L}), 2,4-\mathrm{D}(100 \mathrm{mg} / \mathrm{L})$, BA $(5 \mathrm{mg} / \mathrm{L})$ and thiamine $(1 \mathrm{mg} / \mathrm{L})$. Kunisaki (1989) found that axillary shoots of Leucospermum hybrid were induced to proliferate in a liquid basal medium containing half strength MS inorganic salts, $0.25 \mathrm{mg} / \mathrm{L}$ each of pyridoxine $\mathrm{HCL}$ and nicotinic acid, 0.2 $\mathrm{mg} / \mathrm{L}$ thiamine $\mathrm{HCL}, 2 \%$ sucrose, and $0.2 \mathrm{mg} / \mathrm{L} \mathrm{BA}$.

Table (2): Effect of thiamine, pyridoxine and nicotinic acid, each alone, on shoot number/ explant of Cordyline terminalis in vitro.

\begin{tabular}{|c|c|c|c|c|c|c|c|c|c|}
\hline \multirow{2}{*}{$\begin{array}{c}\text { Vitamin } \\
\text { Concentration } \\
(\mathbf{m g} / \mathrm{L})\end{array}$} & \multicolumn{4}{|c|}{ Thiamine } & \multicolumn{3}{c|}{ Pyridoxine } & \multicolumn{3}{c|}{ Nicotinic Acid } \\
\cline { 2 - 11 } & \multicolumn{3}{|c|}{ Record } & \multicolumn{3}{c|}{ Record } & \multicolumn{3}{c|}{ Record } \\
\cline { 2 - 11 } & 1st & 2nd & 3rd & 1st & 2nd & 3rd & 1st & 2nd & 3rd \\
\hline \multirow{2}{*}{0.00} & $\mathrm{~b}$ & $\mathrm{~b}$ & $\mathrm{a}$ & $\mathrm{a}$ & $\mathrm{b}$ & $\mathrm{b}$ & $\mathrm{a}$ & $\mathrm{a}$ & $\mathrm{b}$ \\
& 2.53 & 4.87 & 12.24 & 2.73 & 5.00 & 12.67 & 2.84 & 5.64 & 11.93 \\
\hline \multirow{2}{*}{0.10} & $\mathrm{a}$ & $\mathrm{a}$ & $\mathrm{a}$ & $\mathrm{a}$ & $\mathrm{a}$ & $\mathrm{a}$ & $\mathrm{a}$ & $\mathrm{a}$ & $\mathrm{a}$ \\
& 2.98 & 5.80 & 12.93 & 3.09 & 6.04 & 14.47 & 3.02 & 5.42 & 13.96 \\
\hline \multirow{2}{*}{0.50} & $\mathrm{a}$ & $\mathrm{ab}$ & $\mathrm{a}$ & $\mathrm{a}$ & $\mathrm{b}$ & $\mathrm{c}$ & $\mathrm{a}$ & $\mathrm{a}$ & $\mathrm{b}$ \\
& 3.22 & 5.47 & 13.07 & 2.91 & 5.09 & 11.16 & 2.87 & 5.07 & 12.36 \\
\hline
\end{tabular}

Concerning pyridoxine, data reveal that, the lower pyridoxine concentration $(0.1 \mathrm{mg} / \mathrm{L})$ mostly showed the significant increase in shoot number in the three records (Fig. 2). Raising the pyridoxine concentration up to $0.50 \mathrm{mg} / \mathrm{L}$ mostly decreased the shoot numbers in the $2^{\text {nd }}$ and $3^{\text {rd }}$ records

As for nicotinic acid, no clear trend can be observed during the $1^{\text {st }}$ and $2^{\text {nd }}$ records with all treatments of nicotinic acid, as they significantly observed similar responses. In the $3^{\text {rd }}$ record data show that nicotinic acid at 
$(0.10 \mathrm{mg} / \mathrm{L})$ showed the significant increase in shoot number when compared to the higher one $(0.50 \mathrm{mg} / \mathrm{L})$ and the control (free of nicotinic acid).

These results are in a harmony with that reported by Kunisaki (1989) who found that axillary shoots of Leucospermum hybrid were induced to proliferate in a liquid basal medium containing half strength of MS inorganic salts, $0.25 \mathrm{mg} / \mathrm{L}$ each of pyridoxine $\mathrm{HCL}$ and nicotinic acid, $0.2 \mathrm{mg} / \mathrm{L}$ thiamine $\mathrm{HCL}, 2 \%$ sucrose, and $0.2 \mathrm{mg} / \mathrm{L} \mathrm{BA}$.

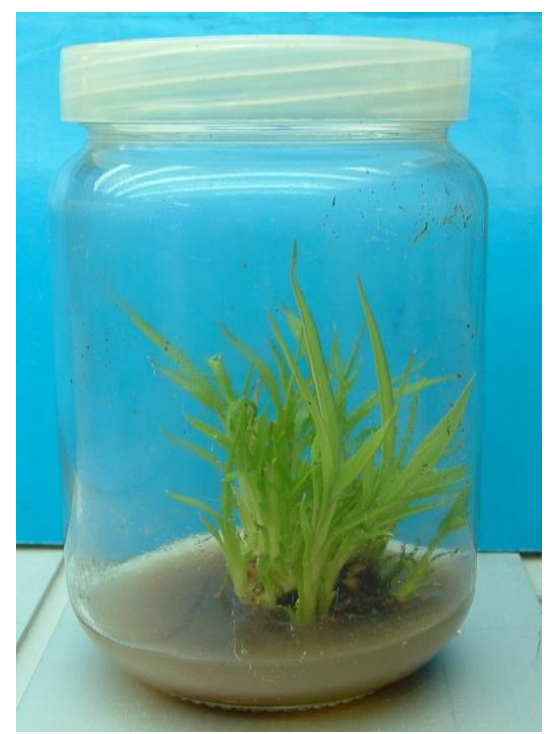

Fig,, (2): Cordyline plantlets grown in the recommended medium contained $1 / 2 \mathrm{MS}+60 \mathrm{~g} / \mathrm{L}$ banana pulp and pyridoxine at 0.1 $\mathrm{mg} / \mathrm{L}$.

\section{A2 - Effect of combination between two vitamins on shoot number. 1-Between thiamine and pyridoxine}

Data presented in Table (3) indicate that, Pyridoxine at $0.10 \mathrm{mg} / \mathrm{L}$ alone showed the highest effect in that concern regardless thiamine during all the three records. However, the first record only showed that the presence of thiamine in the medium was important for shoot proliferation.

\section{2- Between thiamine and nicotinic acid}

Data in Table (4) indicate that thiamine at the concentration 0.10 $\mathrm{mg} / \mathrm{L}$ (in $2^{\text {nd }}$ record only) or $0.50 \mathrm{mg} / \mathrm{L}$ in all records, each alone, proved to be sufficient in increase shoot number. Moreover, when the same levels of thiamine were combined with nicotinic acid at the lower concentration $(0.10$ $\mathrm{mg} / \mathrm{L}$ ) showed similar responses in the increase of shoot number. 
Awad, A. E. et al.

Table (3): Effect of combination between two vitamins on shoot number of Cordyline terminalis.

1- Between thiamine and pyridoxine

\begin{tabular}{|c|c|c|c|c|}
\hline \multicolumn{2}{|c|}{ Vitamins mg/ L } & \multicolumn{3}{|c|}{ Record } \\
\hline Thiamine & Pyridoxine & 1st & 2nd & 3rd \\
\hline \multirow{3}{*}{0.00} & 0.00 & $\begin{array}{c}C \\
2.20\end{array}$ & $\begin{array}{c}\mathrm{d} \\
4.13\end{array}$ & $\begin{array}{c}\mathrm{de} \\
10.67\end{array}$ \\
\hline & 0.10 & $\begin{array}{l}a b c \\
2.87\end{array}$ & $\begin{array}{c}a b \\
5.93\end{array}$ & $\begin{array}{c}\mathrm{a} \\
16.60\end{array}$ \\
\hline & 0.50 & $\begin{array}{c}b c \\
2.53\end{array}$ & $\begin{array}{c}\text { cd } \\
4.53\end{array}$ & $\begin{array}{c}\mathrm{e} \\
9.47\end{array}$ \\
\hline \multirow{3}{*}{0.10} & 0.00 & $\begin{array}{c}\mathrm{ab} \\
3.07\end{array}$ & $\begin{array}{c}\mathrm{ab} \\
5.73\end{array}$ & $\begin{array}{c}b \\
14.20\end{array}$ \\
\hline & 0.10 & $\begin{array}{c}a b \\
3.07\end{array}$ & $\begin{array}{c}\mathrm{a} \\
6.53\end{array}$ & $\begin{array}{c}b c \\
13.20\end{array}$ \\
\hline & 0.50 & $\begin{array}{l}a b c \\
2.80\end{array}$ & $\begin{array}{l}\text { bcd } \\
5.13\end{array}$ & $\begin{array}{c}\text { cde } \\
11.40\end{array}$ \\
\hline \multirow{3}{*}{0.50} & 0.00 & $\begin{array}{c}a b \\
2.93\end{array}$ & $\begin{array}{l}\text { bcd } \\
5.13\end{array}$ & $\begin{array}{c}b c \\
13.00\end{array}$ \\
\hline & 0.10 & $\begin{array}{c}\mathrm{a} \\
3.33\end{array}$ & $\begin{array}{l}a b c \\
5.67\end{array}$ & $\begin{array}{c}\text { bc } \\
13.60\end{array}$ \\
\hline & 0.50 & $\begin{array}{c}\mathrm{a} \\
3.40\end{array}$ & $\begin{array}{l}a b c \\
5.60\end{array}$ & $\begin{array}{c}\mathrm{bcd} \\
12.60\end{array}$ \\
\hline
\end{tabular}

Table (4): Effect of combination between two vitamins on shoot number of Cordyline terminalis.

2- Between thiamine and nicotinic acid

\begin{tabular}{|c|c|c|c|c|}
\hline \multicolumn{2}{|c|}{ Vitamins $\mathbf{~ m g / ~ L ~}$} & \multicolumn{3}{|c|}{ Record } \\
\hline Thiamine & Pyridoxine & 1st & 2nd & 3rd \\
\hline \multirow{3}{*}{0.00} & 0.00 & $\begin{array}{c}c d \\
2.60\end{array}$ & $\begin{array}{c}c d \\
5.13\end{array}$ & $\begin{array}{c}d \\
10.47\end{array}$ \\
\hline & 0.10 & $\begin{array}{c}d \\
2.33\end{array}$ & $\begin{array}{c}d \\
4.27\end{array}$ & $\begin{array}{c}\text { bcd } \\
12.27\end{array}$ \\
\hline & 0.50 & $\begin{array}{l}\text { bcd } \\
2.67\end{array}$ & $\begin{array}{l}\text { bcd } \\
5.20\end{array}$ & $\begin{array}{c}a b c \\
14.00\end{array}$ \\
\hline \multirow{3}{*}{0.10} & 0.00 & $\begin{array}{c}d \\
2.40\end{array}$ & $\begin{array}{l}\text { abcd } \\
5.33\end{array}$ & $\begin{array}{c}d \\
11.47\end{array}$ \\
\hline & 0.10 & $\begin{array}{l}a b c \\
3.20\end{array}$ & $\begin{array}{c}a b \\
6.33\end{array}$ & $\begin{array}{c}a \\
15.40\end{array}$ \\
\hline & 0.50 & $\begin{array}{c}\mathrm{Ab} \\
3.33\end{array}$ & $\begin{array}{l}a b c \\
5.73\end{array}$ & $\begin{array}{c}c d \\
11.93\end{array}$ \\
\hline \multirow{3}{*}{0.50} & 0.00 & $\begin{array}{c}\mathrm{a} \\
3.53\end{array}$ & $\begin{array}{c}\mathrm{a} \\
6.47\end{array}$ & $\begin{array}{c}a b c \\
13.87\end{array}$ \\
\hline & 0.10 & $\begin{array}{c}\mathrm{a} \\
3.53\end{array}$ & $\begin{array}{l}a b c \\
5.67\end{array}$ & $\begin{array}{c}a b \\
14.20\end{array}$ \\
\hline & 0.50 & $\begin{array}{c}c d \\
2.60\end{array}$ & $\begin{array}{c}d \\
4.27\end{array}$ & $\underset{11.13}{d}$ \\
\hline
\end{tabular}

\section{3- Between pyridoxine and nicotinic acid}

Data in Table (5) indicate that, different treatments showed an increase in shoot number, but the only treatment which significantly observed 
that increase during the three records was contained pyridoxine at $0.10 \mathrm{mg} / \mathrm{L}$ combined with nicotinic acid at $0.10 \mathrm{mg} / \mathrm{L}$.

These results are in harmony with that reported by Kunisaki (1989) who found that axillary shoots of Leucospermum hybrid were induced to proliferate in a liquid basal medium contained half strength of MS inorganic salts, $0.25 \mathrm{mg} / \mathrm{L}$ each of pyridoxine $\mathrm{HCL}$ and nicotinic acid, $0.2 \mathrm{mg} / \mathrm{L}$ thiamine $\mathrm{HCL}, 2 \%$ sucrose, and $0.2 \mathrm{mg} / \mathrm{L} \mathrm{BA}$.

.Table (5): Effect of combination between two vitamins on shoot number of Cordyline terminalis.

3- Between pyridoxine and nicotinic acid.

\begin{tabular}{|c|c|c|c|c|}
\hline \multicolumn{2}{|c|}{ Vitamins $\mathrm{mg} / \mathrm{L}$} & \multicolumn{3}{|c|}{ Record } \\
\hline Thiamine & Pyridoxine & 1st & 2nd & 3rd \\
\hline \multirow{3}{*}{0.00} & 0.00 & $\begin{array}{c}b \\
2.47\end{array}$ & $\begin{array}{c}b \\
4.87\end{array}$ & $\begin{array}{c}\text { bcd } \\
11.67\end{array}$ \\
\hline & 0.10 & $\begin{array}{c}a b \\
3.00\end{array}$ & $\begin{array}{c}b \\
5.53\end{array}$ & $\begin{array}{c}b c \\
13.47\end{array}$ \\
\hline & 0.50 & $\begin{array}{c}a b \\
2.73\end{array}$ & $\begin{array}{c}\mathrm{b} \\
4.60\end{array}$ & $\begin{array}{c}b c \\
12.73\end{array}$ \\
\hline \multirow{3}{*}{0.10} & 0.00 & $\begin{array}{c}a b \\
3.07\end{array}$ & $\begin{array}{c}\mathrm{a} \\
6.80\end{array}$ & $\begin{array}{c}b \\
13.73\end{array}$ \\
\hline & 0.10 & $\begin{array}{c}\mathrm{a} \\
3.20\end{array}$ & $\begin{array}{c}a b \\
5.73\end{array}$ & $\begin{array}{c}\mathrm{a} \\
16.67\end{array}$ \\
\hline & 0.50 & $\begin{array}{c}a b \\
3.00\end{array}$ & $\begin{array}{c}b \\
5.60\end{array}$ & $\begin{array}{c}\text { bc } \\
13.00\end{array}$ \\
\hline \multirow{3}{*}{0.50} & 0.00 & $\begin{array}{c}a b \\
3.00\end{array}$ & $\begin{array}{c}b \\
5.27\end{array}$ & $\begin{array}{c}d \\
10.40\end{array}$ \\
\hline & 0.10 & $\begin{array}{c}a b \\
2.87\end{array}$ & $\begin{array}{c}b \\
5.00\end{array}$ & $\begin{array}{c}\text { bcd } \\
11.73\end{array}$ \\
\hline & 0.50 & $\begin{array}{c}a b \\
287\end{array}$ & $\begin{array}{c}b \\
5.00\end{array}$ & $\begin{array}{c}\mathrm{cd} \\
11.33\end{array}$ \\
\hline
\end{tabular}

A3- Effect of combination between thiamine, pyridoxine and nicotinic acid on shoot number/explant of Cordyline terminalis.

Data presented in Table (6) explain that no clear trend could be observed when the three vitamins were added to the medium at various combinations during the three successive records.

\section{B- The effect of vitamins on colour intensity}

\section{B1- Effect of single vitamin on colour intensity.}

Data presented in Table (7) indicate that.

(A) Mostly, the higher thiamine concentration $(0.50 \mathrm{mg} / \mathrm{L})$ increased colour intensity in the three records, the lower concentration $(0.10 \mathrm{mg} / \mathrm{L})$ significantly observed similar results in the $2^{\text {nd }}$ and 3 rd records.

(B) Pyridoxine at both concentrations $(0.10 \mathrm{mg} / \mathrm{L}$ and $0.50 \mathrm{mg} / \mathrm{L})$ increased colour intensity in the three records.

(C) Nicotinic acid at the two concentrations showed similar trend like that recorded with thiamine.

The treatments devoid of vitamins showed lower responses. 
Awad, A. E. et al.

Table (6): Effect of the combination between thiamine, pyridoxine and nicotinic acid (mg/ $\mathrm{L}$ ) on shoot number/explant.

\begin{tabular}{|c|c|c|c|c|c|c|c|c|c|c|}
\hline \multicolumn{2}{|c|}{ Vitamins mg/ L } & \multicolumn{9}{|c|}{ Nicotinic acid $\mathrm{mg} / \mathrm{L}$} \\
\hline \multirow{2}{*}{ Thiamine } & \multirow{2}{*}{ Pyridoxine } & \multicolumn{3}{|c|}{$1^{\text {st }}$ Record } & \multicolumn{3}{|c|}{$2^{\text {nd }}$ Record } & \multicolumn{3}{|c|}{$3^{\text {rd }}$ Record } \\
\hline & & 0.00 & 0.10 & 0.50 & 0.00 & 0.10 & 0.50 & 0.00 & 0.10 & 0.50 \\
\hline \multirow{3}{*}{0.00} & 0.00 & $\begin{array}{l}a b c \\
2.47\end{array}$ & $\begin{array}{l}a b c \\
3.00\end{array}$ & $\begin{array}{l}\text { abc } \\
2.70\end{array}$ & $\begin{array}{c}\mathrm{fg} \\
3.80\end{array}$ & $\begin{array}{l}\text { efg } \\
4.00\end{array}$ & $\begin{array}{l}\text { cdef } \\
4.60\end{array}$ & $\begin{array}{c}\text { hi } \\
9.20\end{array}$ & $\begin{array}{c}\text { ghi } \\
9.80\end{array}$ & $\begin{array}{c}\text { cdef } \\
13.00\end{array}$ \\
\hline & 0.10 & $\begin{array}{l}a b c \\
3.07\end{array}$ & $\begin{array}{c}a b \\
3.20\end{array}$ & $\begin{array}{l}a b c \\
3.00\end{array}$ & $\begin{array}{c}\text { bcde } \\
5.60\end{array}$ & $\begin{array}{l}\text { abcd } \\
6.00\end{array}$ & $\begin{array}{c}\text { abcd } \\
6.20\end{array}$ & $\begin{array}{l}\text { cdefg } \\
13.00\end{array}$ & $\begin{array}{c}\mathrm{a} \\
18.00\end{array}$ & $\begin{array}{c}a \\
18.40\end{array}$ \\
\hline & 0.50 & $\begin{array}{l}a b c \\
3.00\end{array}$ & $\begin{array}{l}a b c \\
2.87\end{array}$ & $\begin{array}{l}a b c \\
2.87\end{array}$ & $\begin{array}{l}\text { abcd } \\
6.00\end{array}$ & $\begin{array}{c}g \\
2.80\end{array}$ & $\begin{array}{c}\text { bcdef } \\
4.80\end{array}$ & $\begin{array}{c}\text { hij } \\
9.20\end{array}$ & $\begin{array}{c}\mathrm{ij} \\
8.60\end{array}$ & $\begin{array}{c}\text { efgh } \\
10.60\end{array}$ \\
\hline \multirow{3}{*}{0.10} & 0.00 & $\begin{array}{c}d \\
0.25\end{array}$ & $\begin{array}{c}b c \\
2.20 \\
\end{array}$ & $\begin{array}{l}a b c \\
2.40\end{array}$ & $\begin{array}{c}\text { bcdef } \\
5.40\end{array}$ & $\begin{array}{l}a b c \\
6.60\end{array}$ & $\begin{array}{c}\text { bcdef } \\
5.20\end{array}$ & $\begin{array}{l}\text { bcde } \\
13.20 \\
\end{array}$ & $\begin{array}{c}a b \\
17.00 \\
\end{array}$ & $\begin{array}{l}\text { defgh } \\
12.40 \\
\end{array}$ \\
\hline & 0.10 & $\begin{array}{l}a b c \\
2.80\end{array}$ & $\begin{array}{l}a b c \\
2.80\end{array}$ & $\begin{array}{l}a b c \\
3.00\end{array}$ & $\begin{array}{c}a b \\
6.80\end{array}$ & $\begin{array}{l}\mathrm{abc} \\
6.40\end{array}$ & $\begin{array}{l}a b c \\
6.40\end{array}$ & $\begin{array}{l}\text { bcde } \\
13.80\end{array}$ & $\begin{array}{c}a b c \\
15.20 \\
\end{array}$ & $\begin{array}{c}\text { efgh } \\
10.60\end{array}$ \\
\hline & 0.50 & $\begin{array}{l}\text { abc } \\
3.00\end{array}$ & $\begin{array}{c}c \\
2.00\end{array}$ & $\begin{array}{l}a b c \\
2.60\end{array}$ & $\begin{array}{c}\mathrm{fg} \\
3.80\end{array}$ & $\begin{array}{c}\text { abcde } \\
6.00\end{array}$ & $\begin{array}{c}\text { bcde } \\
5.60\end{array}$ & $\begin{array}{c}\mathrm{j} \\
7.40\end{array}$ & $\begin{array}{l}\text { bcde } \\
14.00 \\
\end{array}$ & $\begin{array}{c}\text { cdef } \\
12.80\end{array}$ \\
\hline \multirow{3}{*}{0.50} & 0.00 & $\begin{array}{l}a b c \\
2.40\end{array}$ & $\begin{array}{c}\mathrm{a} \\
3.40\end{array}$ & $\begin{array}{c}\mathrm{a} \\
3.40\end{array}$ & $\begin{array}{c}\text { bcde } \\
5.40\end{array}$ & $\begin{array}{l}\text { abcd } \\
6.00\end{array}$ & $\begin{array}{c}\text { efg } \\
4.00\end{array}$ & $\begin{array}{l}\text { cdefg } \\
12.60\end{array}$ & $\begin{array}{l}\text { bcdef } \\
13.60\end{array}$ & $\begin{array}{c}\text { cdef } \\
12.80\end{array}$ \\
\hline & 0.10 & $\begin{array}{l}a b c \\
2.60\end{array}$ & $\begin{array}{c}a b \\
3.20\end{array}$ & $\begin{array}{c}\mathrm{a} \\
3.40\end{array}$ & $\begin{array}{c}\mathrm{a} \\
8.00\end{array}$ & $\begin{array}{l}\text { bcde } \\
4.80\end{array}$ & $\begin{array}{l}\text { defg } \\
4.20\end{array}$ & $\begin{array}{l}\text { bcdef } \\
14.40\end{array}$ & $\begin{array}{c}a b c \\
16.40\end{array}$ & $\begin{array}{c}\text { fghi } \\
10.00\end{array}$ \\
\hline & 0.50 & $\begin{array}{c}b c \\
2.20\end{array}$ & $\begin{array}{l}a b c \\
3.00\end{array}$ & $\begin{array}{c}a b \\
3.20\end{array}$ & $\begin{array}{l}\text { abcd } \\
6.00\end{array}$ & $\begin{array}{l}\text { abcd } \\
6.20\end{array}$ & $\begin{array}{l}\text { cde } \\
4.60\end{array}$ & $\begin{array}{l}\text { abcd } \\
14.60\end{array}$ & $\begin{array}{c}\text { cdef } \\
12.60\end{array}$ & $\begin{array}{l}\text { efghi } \\
10.60 \\
\end{array}$ \\
\hline
\end{tabular}

Table (7): Effect of thiamine, Pyridoxine and nicotinic acid, each alone, on colour intensity of Cordyline terminals explants.

\begin{tabular}{|c|c|c|c|c|c|c|c|c|c|}
\hline \multirow{3}{*}{$\begin{array}{c}\text { Vitamin } \\
\text { Concentration } \\
\text { mg/L }\end{array}$} & \multicolumn{9}{|c|}{ Single Vitamin } \\
\cline { 2 - 10 } & \multicolumn{3}{|c|}{ Record } & \multicolumn{3}{c|}{ Record } & \multicolumn{3}{c|}{ Record } \\
\cline { 2 - 10 } & 1st & 2nd & 3rd & 1st & 2nd & 3rd & 1st & 2nd & 3rd \\
\hline \multirow{2}{*}{0.00} & $\mathrm{c}$ & $\mathrm{b}$ & $\mathrm{b}$ & $\mathrm{b}$ & $\mathrm{b}$ & $\mathrm{b}$ & $\mathrm{b}$ & $\mathrm{b}$ & $\mathrm{b}$ \\
& 2.91 & 3.33 & 2.96 & 3.00 & 3.18 & 3.07 & 3.00 & 3.38 & 3.18 \\
\hline \multirow{2}{*}{0.10} & $\mathrm{~b}$ & $\mathrm{a}$ & $\mathrm{a}$ & $\mathrm{a}$ & $\mathrm{a}$ & $\mathrm{a}$ & $\mathrm{b}$ & $\mathrm{a}$ & $\mathrm{a}$ \\
& 3.20 & 3.62 & 3.44 & 3.31 & 3.73 & 3.51 & 3.36 & 3.62 & 3.47 \\
\hline \multirow{2}{*}{0.50} & $\mathrm{a}$ & $\mathrm{a}$ & $\mathrm{a}$ & $\mathrm{a}$ & $\mathrm{a}$ & $\mathrm{a}$ & $\mathrm{a}$ & $\mathrm{a}$ & $\mathrm{b}$ \\
& 3.62 & 3.67 & 3.51 & 3.42 & 3.71 & 3.33 & 3.38 & 3.62 & 3.27 \\
\hline
\end{tabular}

B2- Effect of combination between two vitamins on colour intensity.

\section{1- Between thiamine and pyridoxine}

Data presented in Table (8) indicate that, some different treatments were effective in enhancing the colour intensity of Cordyline terminals cultures, but the only treatment that showed that effect during the three records contained thiamine with pyridoxine at the higher concentrations of both $(0.5 \mathrm{mg} / \mathrm{L})$.

2- Between thiamine and nicotinic acid

Data in Table (9) explain that, Sporadic responses were observed with some different treatments, but mostly results indicated the combination between thiamine and nicotinic acid was effective in enhancing the colour 
J. Agric. Sci. Mansoura Univ., 33 (3), March, 2008

intensity, except the treatment of thiamine alone at $0.5 \mathrm{mg} / \mathrm{L}$ that significantly showed similar higher effect in that concern.

Table (8): Effect of combination between two vitamins on colour intensity.

1- Between thiamine and pyridoxine

\begin{tabular}{|c|c|c|c|c|}
\hline \multicolumn{2}{|c|}{ Vitamin Concentration mg/L } & \multicolumn{3}{|c|}{ Record } \\
\hline Thiamine & Pyridoxine & 1st & 2nd & 3rd \\
\hline \multirow{3}{*}{0.00} & 0.00 & $\begin{array}{c}f \\
2.60\end{array}$ & $\begin{array}{c}\mathrm{e} \\
2.93\end{array}$ & $\begin{array}{c}c \\
2.33\end{array}$ \\
\hline & 0.10 & $\begin{array}{c}c \mathrm{~cd} \\
3.20\end{array}$ & $\begin{array}{c}\mathrm{ab} \\
3.87\end{array}$ & $\begin{array}{c}\mathrm{a} \\
3.60\end{array}$ \\
\hline & 0.50 & $\begin{array}{c}\mathrm{de} \\
2.93\end{array}$ & $\begin{array}{c}\mathrm{de} \\
3.20\end{array}$ & $\begin{array}{c}b \\
2.93\end{array}$ \\
\hline \multirow{3}{*}{0.10} & 0.00 & $\begin{array}{c}\text { ef } \\
2.87\end{array}$ & $\begin{array}{c}\mathrm{de} \\
3.20\end{array}$ & $\begin{array}{c}\mathrm{a} \\
3.33 \\
\end{array}$ \\
\hline & 0.10 & $\begin{array}{c}\text { bc } \\
3.27\end{array}$ & $\begin{array}{l}a b c \\
3.73\end{array}$ & $\begin{array}{c}\mathrm{a} \\
3.53\end{array}$ \\
\hline & 0.50 & $\begin{array}{c}b c \\
3.47\end{array}$ & $\begin{array}{c}\mathrm{ab} \\
3.93\end{array}$ & $\begin{array}{c}\mathrm{a} \\
3.47\end{array}$ \\
\hline \multirow{3}{*}{0.50} & 0.00 & $\begin{array}{c}b \\
3.53\end{array}$ & $\begin{array}{c}c d \\
3.40\end{array}$ & $\begin{array}{c}\mathrm{a} \\
3.53\end{array}$ \\
\hline & 0.10 & $\begin{array}{c}\text { bc } \\
3.47\end{array}$ & $\begin{array}{c}b c \\
3.60\end{array}$ & $\begin{array}{c}\mathrm{a} \\
3.40\end{array}$ \\
\hline & 0.50 & $\begin{array}{c}a \\
3.87\end{array}$ & $\begin{array}{c}\mathrm{a} \\
4.00\end{array}$ & $\begin{array}{c}\mathrm{a} \\
3.60\end{array}$ \\
\hline
\end{tabular}

Table (9): Effect of combination between two vitamins on colour intensity.

2- Between thiamine and nicotinic acid

\begin{tabular}{|c|c|c|c|c|}
\hline \multicolumn{2}{|c|}{ Vitamin Concentration mg/L } & \multicolumn{3}{|c|}{ Record } \\
\hline Thiamine & Nicotinic acid & 1st & 2nd & 3rd \\
\hline \multirow{3}{*}{0.00} & 0.00 & $\begin{array}{c}\mathrm{e} \\
2.60\end{array}$ & $\begin{array}{c}d \\
3.20\end{array}$ & $\begin{array}{c}d \\
2.87\end{array}$ \\
\hline & 0.10 & $\begin{array}{c}c d \\
3.20\end{array}$ & $\begin{array}{l}\text { bcd } \\
3.47\end{array}$ & $\begin{array}{c}c d \\
3.00\end{array}$ \\
\hline & 0.50 & $\begin{array}{c}d \\
2.93\end{array}$ & $\begin{array}{c}c c d \\
3.33\end{array}$ & $\begin{array}{c}c c d \\
3.00\end{array}$ \\
\hline \multirow{3}{*}{0.10} & 0.00 & $\begin{array}{c}c \mathrm{~cd} \\
3.07\end{array}$ & $\begin{array}{l}\text { bcd } \\
3.47\end{array}$ & $\begin{array}{c}c d \\
3.07\end{array}$ \\
\hline & 0.10 & $\begin{array}{c}b c \\
3.33\end{array}$ & $\begin{array}{c}\mathrm{ab} \\
3.73\end{array}$ & $\begin{array}{c}\mathrm{a} \\
3.73\end{array}$ \\
\hline & 0.50 & $\begin{array}{c}c c d \\
3.20\end{array}$ & $\begin{array}{c}a b c \\
3.67\end{array}$ & $\begin{array}{c}\mathrm{ab} \\
3.53\end{array}$ \\
\hline \multirow{3}{*}{0.50} & 0.00 & $\begin{array}{c}b c \\
3.33\end{array}$ & $\begin{array}{l}\text { bcd } \\
3.47\end{array}$ & $\begin{array}{c}\mathrm{a} \\
3.60\end{array}$ \\
\hline & 0.10 & $\begin{array}{c}b \\
3.53\end{array}$ & $\begin{array}{l}a b c \\
3.67\end{array}$ & $\begin{array}{c}\mathrm{a} \\
3.66\end{array}$ \\
\hline & 0.50 & $\begin{array}{c}\mathrm{a} \\
4.00\end{array}$ & $\begin{array}{c}\mathrm{a} \\
3.87\end{array}$ & $\begin{array}{c}\text { bc } \\
3.27\end{array}$ \\
\hline
\end{tabular}


Awad, A. E. et al.

3- Between pyridoxine and nicotinic acid

Data in Table (10) indicate that Pyridoxine at $0.10 \mathrm{mg} / \mathrm{L}$ when combined with nicotinic acid at $0.10 \mathrm{mg} / \mathrm{L}$ significantly increased colour intensity in the new growth of Cordyline terminals explants, in the three records.

Table (10): Effect of combination between two vitamins on colour intensity.

3- $\quad$ Between pyridoxine and nicotinic acid.

\begin{tabular}{|c|c|c|c|c|}
\hline \multicolumn{2}{|c|}{ Vitamin Concentration $\mathrm{mg} / \mathrm{L}$} & \multicolumn{3}{|c|}{ Record } \\
\hline Pyridoxine & Nicotinic acid & 1st & 2nd & 3rd \\
\hline \multirow{3}{*}{0.00} & 0.00 & $\begin{array}{c}C \\
2.87\end{array}$ & $\begin{array}{c}\mathrm{de} \\
3.07\end{array}$ & $\begin{array}{c}b c \\
3.13\end{array}$ \\
\hline & 0.10 & $\begin{array}{c}c \\
2.87\end{array}$ & $\begin{array}{c}\mathrm{e} \\
3.00\end{array}$ & $\begin{array}{c}c \\
2.93\end{array}$ \\
\hline & 0.50 & $\begin{array}{c}b \\
3.27\end{array}$ & $\begin{array}{c}b c \\
3.47\end{array}$ & $\begin{array}{c}b c \\
3.13\end{array}$ \\
\hline \multirow{3}{*}{0.10} & 0.00 & $\begin{array}{c}c \\
2.80 \\
2.80\end{array}$ & $\begin{array}{c}c d \\
3.40\end{array}$ & $\begin{array}{c}b c \\
3.13\end{array}$ \\
\hline & 0.10 & $\begin{array}{c}\mathrm{a} \\
3.80\end{array}$ & $\begin{array}{c}\mathrm{a} \\
4.20\end{array}$ & $\begin{array}{c}\mathrm{a} \\
4.13\end{array}$ \\
\hline & 0.50 & $\begin{array}{c}b \\
3.33\end{array}$ & $\begin{array}{c}b c \\
3.60\end{array}$ & $\begin{array}{c}b \\
3.27\end{array}$ \\
\hline \multirow{3}{*}{0.50} & 0.00 & $\begin{array}{c}b \\
3.33\end{array}$ & $\begin{array}{c}\mathrm{bc} \\
3.67\end{array}$ & $\begin{array}{c}b \\
3.27\end{array}$ \\
\hline & 0.10 & $\begin{array}{c}b \\
3.40\end{array}$ & $\begin{array}{c}b c \\
3.67\end{array}$ & $\begin{array}{c}b \\
3.33\end{array}$ \\
\hline & 0.50 & $\begin{array}{c}a b \\
3.53\end{array}$ & $\begin{array}{c}b \\
3.80\end{array}$ & $\begin{array}{c}b \\
3.40\end{array}$ \\
\hline
\end{tabular}

$B_{3}$ - Effect of the combination between thiamine, pyridoxine and nicotinic acid on colour intensity:

Data presented in Table (11) clearly indicate that no clear trend could be observed when the three vitamins were added to the medium at various combinations during the three successive records.

\section{C- The effect on growth vigor.}

C1- Effect of single vitamin on growth vigor.

Data in Table (12) indicate that, Thiamine at both $0.10 \mathrm{mg} / \mathrm{L}$ and $0.50 \mathrm{mg} / \mathrm{L}$ mostly enhanced growth vigor when compared to control media, in the three records. The obtained results are in agreement with that reported by Beruto et al. (1983) who recorded that buds of Cordyline terminals were cultured on Murashige and Skooge medium with $0.5 \mathrm{mg} / \mathrm{L}$ thiamine $\mathrm{HCL}$ and $0.1 \mathrm{mg} / \mathrm{L}$ BA for 3-4 weeks. Curir et al. (1990) mentioned that Embryogenesis occurred on medium containing glycine, calcium panthothenate, thiamine- HCL, myoinositol, zeatin and NAA. 
Table (11): Effect of the combination between thiamine, pyridoxine and nicotinic acid on colour intensity

\begin{tabular}{|c|c|c|c|c|c|c|c|c|c|c|}
\hline \multicolumn{2}{|c|}{\begin{tabular}{|c|} 
Vitamin \\
Concentration $\mathrm{mg} / \mathrm{L}$ \\
\end{tabular}} & \multicolumn{9}{|c|}{ Nicotinic acid ( $\mathrm{mg} / \mathrm{L}$ ) } \\
\hline \multirow[t]{2}{*}{ Thiamine } & \multirow{2}{*}{ Pyridoxine } & \multicolumn{3}{|c|}{$1^{\text {st }}$ Record } & \multicolumn{3}{|c|}{$2^{\text {nd }}$ Record } & \multicolumn{3}{|c|}{$3^{\text {rd }}$ Record } \\
\hline & & 0.00 & 0.10 & 0.50 & 0.00 & 0.10 & 0.50 & 0.00 & 0.10 & 0.50 \\
\hline \multirow{3}{*}{0.00} & 0.00 & $\begin{array}{c}e \\
2.40 \\
\end{array}$ & $\begin{array}{c}d e \\
2.60\end{array}$ & $\begin{array}{l}\text { cde } \\
2.80\end{array}$ & $\begin{array}{c}g \\
2.60 \\
\end{array}$ & $\begin{array}{c}\mathrm{bg} \\
2.80 \\
\end{array}$ & $\begin{array}{l}\text { def } \\
3.40 \\
\end{array}$ & $\begin{array}{c}i \\
2.20 \\
\end{array}$ & $\begin{array}{c}i \\
2.20 \\
\end{array}$ & $\begin{array}{r}\mathrm{hi} \\
2.60 \\
\end{array}$ \\
\hline & 0.10 & $\begin{array}{c}d e \\
2.60\end{array}$ & $\begin{array}{c}\mathrm{a} \\
4.00 \\
\end{array}$ & $\begin{array}{c}\mathrm{cd} \\
3.00\end{array}$ & $\begin{array}{l}\text { cde } \\
3.60\end{array}$ & $\begin{array}{c}\mathrm{ab} \\
4.40\end{array}$ & $\begin{array}{l}\text { cde } \\
3.60\end{array}$ & $\begin{array}{l}\text { def } \\
3.40\end{array}$ & $\begin{array}{l}a b c \\
4.00 \\
\end{array}$ & $\begin{array}{r}\text { def } \\
3.40 \\
\end{array}$ \\
\hline & 0.50 & $\begin{array}{l}\text { cde } \\
2.80\end{array}$ & $\begin{array}{c}\mathrm{cd} \\
3.00\end{array}$ & $\begin{array}{c}c c d \\
3.00\end{array}$ & $\begin{array}{c}\text { def } \\
3.40\end{array}$ & $\begin{array}{l}\text { defg } \\
3.20 \\
\end{array}$ & $\begin{array}{l}\text { efg } \\
3.00 \\
\end{array}$ & $\begin{array}{l}\text { fgh } \\
3.00\end{array}$ & $\begin{array}{l}\text { gh } \\
2.80\end{array}$ & $\begin{array}{l}\text { fgh } \\
3.00 \\
\end{array}$ \\
\hline \multirow{3}{*}{0.10} & 0.00 & $\begin{array}{c}d e \\
2.60\end{array}$ & $\begin{array}{c}\mathrm{cd} \\
3.00\end{array}$ & $\begin{array}{c}\mathrm{cd} \\
3.00\end{array}$ & $\begin{array}{l}\text { efg } \\
3.00\end{array}$ & $\begin{array}{l}\text { defg } \\
3.20\end{array}$ & $\begin{array}{l}\text { def } \\
3.40\end{array}$ & $\begin{array}{l}\mathrm{gh} \\
2.80\end{array}$ & $\begin{array}{l}\text { cde } \\
3.60\end{array}$ & $\begin{array}{l}\text { cde } \\
3.60\end{array}$ \\
\hline & 0.10 & $\begin{array}{c}c c d \\
3.00\end{array}$ & $\begin{array}{c}\mathrm{a} \\
3.80\end{array}$ & $\begin{array}{c}c \mathrm{~cd} \\
3.00\end{array}$ & $\begin{array}{l}\text { defg } \\
3.20\end{array}$ & $\begin{array}{c}\mathrm{a} \\
4.60\end{array}$ & $\begin{array}{l}\text { def } \\
3.40\end{array}$ & $\begin{array}{l}\text { fgh } \\
3.00\end{array}$ & $\begin{array}{c}\mathrm{ab} \\
4.20\end{array}$ & $\begin{array}{r}\text { def } \\
3.40 \\
\end{array}$ \\
\hline & 0.50 & $\begin{array}{c}a b \\
3.60\end{array}$ & $\begin{array}{c}b c \\
3.20\end{array}$ & $\begin{array}{c}a b \\
3.60\end{array}$ & $\begin{array}{l}a b c \\
4.20 \\
\end{array}$ & $\begin{array}{c}\text { def } \\
3.40\end{array}$ & $\begin{array}{l}\mathrm{abc} \\
4.20\end{array}$ & $\begin{array}{l}\text { def } \\
3.40\end{array}$ & $\begin{array}{c}\text { def } \\
3.40\end{array}$ & $\begin{array}{c}\text { cde } \\
3.60\end{array}$ \\
\hline \multirow{3}{*}{0.50} & 0.00 & $\begin{array}{c}\mathrm{ab} \\
3.60\end{array}$ & $\begin{array}{c}\mathrm{cd} \\
3.00\end{array}$ & $\begin{array}{c}\mathrm{a} \\
4.00 \\
\end{array}$ & $\begin{array}{c}\text { cde } \\
3.60\end{array}$ & $\begin{array}{c}\text { efg } \\
3.00\end{array}$ & $\begin{array}{c}\text { cde } \\
3.60\end{array}$ & $\begin{array}{c}\mathrm{a} \\
4.40\end{array}$ & $\begin{array}{c}\text { fgh } \\
3.00\end{array}$ & $\begin{array}{c}\text { efg } \\
3.20\end{array}$ \\
\hline & 0.10 & $\begin{array}{l}\text { cde } \\
2.80\end{array}$ & $\begin{array}{c}a b \\
3.60\end{array}$ & $\begin{array}{c}\mathrm{a} \\
4.00 \\
\end{array}$ & $\begin{array}{c}\text { def } \\
3.40\end{array}$ & $\begin{array}{c}\text { cde } \\
3.60\end{array}$ & $\begin{array}{l}\text { bcd } \\
3.80\end{array}$ & $\begin{array}{l}\text { fgh } \\
3.00\end{array}$ & $\begin{array}{c}a b \\
4.20\end{array}$ & $\begin{array}{c}\text { fgh } \\
3.00\end{array}$ \\
\hline & 0.50 & $\begin{array}{c}\mathrm{ab} \\
3.60\end{array}$ & $\begin{array}{c}\mathrm{a} \\
4.00\end{array}$ & $\begin{array}{c}\mathrm{a} \\
4.00\end{array}$ & $\begin{array}{c}\text { def } \\
3.40\end{array}$ & $\begin{array}{c}\mathrm{ab} \\
4.40\end{array}$ & $\begin{array}{l}\mathrm{abc} \\
4.20\end{array}$ & $\begin{array}{c}\text { def } \\
3.40\end{array}$ & $\begin{array}{l}\text { bcd } \\
3.80\end{array}$ & $\begin{array}{l}\text { cde } \\
3.60\end{array}$ \\
\hline
\end{tabular}

Table (12): Effect of thiamine, pyridoxine and nicotinic acid, each alone, on growth vigor during three records

\begin{tabular}{|c|c|c|c|c|c|c|c|c|c|}
\hline \multirow{3}{*}{$\begin{array}{c}\text { Vitamin } \\
\text { Concentration } \\
\mathbf{m g} / \mathbf{L}\end{array}$} & \multicolumn{4}{|c|}{ Thiamine } & \multicolumn{4}{c|}{ Pyridoxine } & \multicolumn{3}{c|}{ Nicotinic Acid } \\
\cline { 2 - 10 } & \multicolumn{3}{|c|}{ Record } & \multicolumn{3}{c|}{ Record } & \multicolumn{3}{c|}{ Record } \\
\cline { 2 - 11 } & 1st & 2nd & 3rd & 1st & 2nd & 3rd & 1st & 2nd & 3rd \\
\hline \multirow{2}{*}{0.00} & $\mathrm{c}$ & $\mathrm{b}$ & $\mathrm{b}$ & $\mathrm{b}$ & $\mathrm{b}$ & $\mathrm{b}$ & $\mathrm{a}$ & $\mathrm{a}$ & $\mathrm{ab}$ \\
& 2.53 & 3.00 & 2.84 & 2.89 & 3.16 & 2.71 & 3.02 & 3.47 & 3.04 \\
\hline 0.10 & $\mathrm{~b}$ & $\mathrm{a}$ & $\mathrm{a}$ & $\mathrm{a}$ & $\mathrm{a}$ & $\mathrm{a}$ & $\mathrm{a}$ & $\mathrm{a}$ & $\mathrm{a}$ \\
& 3.31 & 3.80 & 3.49 & 3.29 & 3.76 & 3.31 & 3.16 & 3.51 & 3.20 \\
\hline \multirow{2}{*}{0.50} & $\mathrm{a}$ & $\mathrm{a}$ & $\mathrm{a}$ & $\mathrm{a}$ & $\mathrm{a}$ & $\mathrm{a}$ & $\mathrm{a}$ & $\mathrm{a}$ & $\mathrm{a}$ \\
& 3.44 & 3.80 & 2.89 & 3.16 & 3.69 & 3.20 & 3.16 & 3.62 & 2.98 \\
\hline
\end{tabular}

Pyridoxine at 0.10 and $0.50 \mathrm{mg} / \mathrm{L}$ significantly increased growth vigor in the three records.

Nicotinic acid at $0.10 \mathrm{mg} / \mathrm{L}$ significantly increased growth vigor in three records, followed by the higher $(0.5 \mathrm{mg} / \mathrm{L})$ concentration. These results agreed with that reported by Soczek and Hempel (1988) who stated that shoots of the cultivars clementine, saskia and terravise were multiplied on MS media without or with the addition of thiamin, Pyridoxine, nicotinic acid myoinositol, tyrosine and adenine sulphate, in the original strength or in concentrations reduced to one-half or one-quarter. 
Awad, A. E. et al.

\section{C2: Effect of combination between two vitamins on the growth vigor. \\ 1- Between thiamine and pyridoxine}

Data in Table (13) indicate that thiamine at $0.10 \mathrm{mg} / \mathrm{L}$ when combined with pyridoxine at $0.10 \mathrm{mg} / \mathrm{L}$ or $0.50 \mathrm{mg} / \mathrm{L}$ significantly enhanced the growth vigor in the three records. Similar result was obtained in the $1^{\text {st }}$ record only when the medium contained the highest concentration $(0.5 \mathrm{mg} / \mathrm{L})$ of both vitamins. In that concern, Wang and Ma (1978) found that shoot apical meristem $(0.2-0.1 \mathrm{~mm})$ of chrysanthemum when cultured on medium supplemented with myoinositol at $100 \mathrm{mg} / \mathrm{L}$, thiamine at $1 \mathrm{mg} / \mathrm{L}$, pyridoxine at $5 \mathrm{mg} / \mathrm{L}$, nicotinic acid at $5 \mathrm{mg} / \mathrm{L}, \mathrm{NAA}$ at $0.3 \mathrm{mg} / \mathrm{L}$, kinetin at $0.1 \mathrm{mg} / \mathrm{L}$, adenine sulphate at $40 \mathrm{mg} / \mathrm{L}$ and malt extract at $400 \mathrm{mg} / \mathrm{L}$, first followed callus formation, followed by a single shoot which arose from the centre part of the explant.

Table (13): Effect of combination between two vitamins on the growth vigor. 1- Between thiamine and pyridoxine

\begin{tabular}{|c|c|c|c|c|}
\hline \multicolumn{2}{|c|}{ Vitamin Concentration $\mathrm{mg} / \mathrm{L}$} & \multicolumn{3}{|c|}{ Record } \\
\hline Thiamine & Pyridoxine & 1st & 2nd & 3rd \\
\hline \multirow{3}{*}{0.00} & 0.00 & $\begin{array}{c}\mathrm{C} \\
2.27 \\
\end{array}$ & $\begin{array}{c}d \\
2.33\end{array}$ & $\begin{array}{c}c \\
2.20 \\
\end{array}$ \\
\hline & 0.10 & $\begin{array}{c}\mathrm{b} \\
3.00\end{array}$ & $\begin{array}{c}\mathrm{b} \\
3.60\end{array}$ & $\begin{array}{c}\mathrm{a} \\
3.47\end{array}$ \\
\hline & 0.50 & $\begin{array}{c}c \\
2.33\end{array}$ & $\begin{array}{c}c \\
3.07\end{array}$ & $\begin{array}{c}b \\
2.87\end{array}$ \\
\hline \multirow{3}{*}{0.10} & 0.00 & $\begin{array}{c}\mathrm{b} \\
3.00\end{array}$ & $\begin{array}{c}c \\
.20 \\
3.20\end{array}$ & $\begin{array}{c}b \\
3.07\end{array}$ \\
\hline & 0.10 & $\begin{array}{c}\mathrm{a} \\
3.47\end{array}$ & $\begin{array}{c}\mathrm{a} \\
4.07\end{array}$ & $\begin{array}{c}\mathrm{a} \\
3.60\end{array}$ \\
\hline & 0.50 & $\begin{array}{c}\mathrm{a} \\
3.47\end{array}$ & $\begin{array}{c}a \\
4.13 \\
\end{array}$ & $\begin{array}{c}\mathrm{a} \\
3.80 \\
\end{array}$ \\
\hline \multirow{3}{*}{0.50} & 0.00 & $\begin{array}{c}\mathrm{a} \\
3.40\end{array}$ & $\begin{array}{c}b \\
3.93\end{array}$ & $\begin{array}{c}b \\
2.87\end{array}$ \\
\hline & 0.10 & $\begin{array}{c}\mathrm{a} \\
3.40\end{array}$ & $\begin{array}{c}b \\
3.60\end{array}$ & $\begin{array}{c}b \\
2.87\end{array}$ \\
\hline & 0.50 & $\begin{array}{c}\mathrm{a} \\
3.67\end{array}$ & $\begin{array}{c}b \\
3.87\end{array}$ & $\begin{array}{c}b \\
2.93\end{array}$ \\
\hline
\end{tabular}

\section{2- Between thiamine and nicotinic acid}

Data in Table (14) indicate that thiamine at $0.10 \mathrm{mg} / \mathrm{L}$ when combined with nicotinic acid at 0.10 or $0.50 \mathrm{mg} / \mathrm{L}$ significantly increased the growth in the $2^{\text {nd }}$ and $3^{\text {rd }}$ records. Significantly similar result was obtained in the $1^{\text {st }}$ and $2^{\text {nd }}$ records when thiamine at $0.50 \mathrm{mg} / \mathrm{L}$ combined with $0.50 \mathrm{mg} / \mathrm{L}$ nicotinic acid. Lower responses were recorded with the other treatments. The importance if vitamin in the medium was reported by Wang and Ma (1978) who found that shoot apical meristem $(0.2-0.1 \mathrm{~mm})$ of chrysanthemum when cultured on medium supplemented with myoinositol at $100 \mathrm{mg} / \mathrm{L}$, thiamine at $1 \mathrm{mg} / \mathrm{L}$, pyridoxine at $5 \mathrm{mg} / \mathrm{L}$, nicotinic acid at $5 \mathrm{mg} / \mathrm{L}, \mathrm{NAA}$ at $0.3 \mathrm{mg} / \mathrm{L}$, kinetin at $0.1 \mathrm{mg} / \mathrm{L}$, adenine sulphate at $40 \mathrm{mg} / \mathrm{L}$ and malt extract at $400 \mathrm{mg} / \mathrm{L}$, first followed callus formation, followed by a single shoot which arose from the centre part of the explant. 
J. Agric. Sci. Mansoura Univ., 33 (3), March, 2008

Table (14): Effect of combination between two vitamins on the growth vigor 2- Between thiamine and nicotinic acid

\begin{tabular}{|c|c|c|c|c|}
\hline \multirow{2}{*}{$\begin{array}{c}\text { Thiamine } \\
\mathrm{mg} / \mathrm{L}\end{array}$} & \multirow{2}{*}{$\begin{array}{c}\text { Nicotinic acid } \\
\mathrm{mg} / \mathrm{L}\end{array}$} & \multicolumn{3}{|c|}{ Record } \\
\hline & & 1st & 2nd & 3rd \\
\hline \multirow{3}{*}{0.00} & 0.00 & $\begin{array}{c}c d \\
2.53\end{array}$ & $\begin{array}{c}c \\
3.00\end{array}$ & $\begin{array}{c}\text { de } \\
2.93\end{array}$ \\
\hline & 0.10 & $\begin{array}{c}c \\
2.73\end{array}$ & $\begin{array}{c}c \\
3.07\end{array}$ & $\begin{array}{c}e \\
2.80\end{array}$ \\
\hline & 0.50 & $\begin{array}{c}d \\
2.33\end{array}$ & $\begin{array}{c}c \\
2.93\end{array}$ & $\begin{array}{c}e \\
2.80\end{array}$ \\
\hline \multirow{3}{*}{0.10} & 0.00 & $\begin{array}{c}b \\
3.33\end{array}$ & $\begin{array}{c}b \\
3.60\end{array}$ & $\begin{array}{l}\text { bcd } \\
3.20\end{array}$ \\
\hline & 0.10 & $\begin{array}{c}\mathrm{b} \\
3.33 \\
\end{array}$ & $\begin{array}{c}a b \\
3.73 \\
\end{array}$ & $\begin{array}{l}\mathrm{ab} \\
3.47\end{array}$ \\
\hline & 0.50 & $\begin{array}{c}b \\
3.27\end{array}$ & $\begin{array}{c}\mathrm{a} \\
4.07\end{array}$ & $\begin{array}{c}\mathrm{a} \\
3.80\end{array}$ \\
\hline \multirow{3}{*}{0.50} & 0.00 & $\begin{array}{c}\mathrm{b} \\
3.20\end{array}$ & $\begin{array}{c}a b \\
3.80\end{array}$ & $\begin{array}{l}\text { cde } \\
3.00\end{array}$ \\
\hline & 0.10 & $\begin{array}{c}\mathrm{b} \\
3.40\end{array}$ & $\begin{array}{c}a b \\
3.73\end{array}$ & $\begin{array}{c}\text { be } \\
3.33\end{array}$ \\
\hline & 0.50 & $\begin{array}{c}a \\
3.87\end{array}$ & $\begin{array}{c}a b \\
3.87\end{array}$ & $\begin{array}{c}f \\
2.33\end{array}$ \\
\hline
\end{tabular}

\section{3- Between pyridoxine and nicotinic acid}

Data in Table (15) indicate that pyridoxine at $0.10 \mathrm{mg} / \mathrm{L}$ when combined with nicotinic acid at 0.10 significantly increased the growth vigor in the three records.

Table (15): Effect of combination between two vitamins on the growth vigor. Between pyridoxine and nicotinic acid.

\begin{tabular}{|c|c|c|c|c|}
\hline \multirow{2}{*}{$\begin{array}{l}\text { Pyridoxine } \\
\mathrm{mg} / \mathrm{L}\end{array}$} & \multirow{2}{*}{$\begin{array}{c}\text { Nicotinic acid } \\
\mathrm{mg} / \mathrm{L}\end{array}$} & \multicolumn{3}{|c|}{ Record } \\
\hline & & 1st & 2nd & 3rd \\
\hline \multirow{3}{*}{0.00} & 0.00 & $\begin{array}{c}d \\
2.80\end{array}$ & $\begin{array}{c}d \\
3.33\end{array}$ & $\begin{array}{c}\mathrm{de} \\
2.70\end{array}$ \\
\hline & 0.10 & $\begin{array}{c}d \\
2.80\end{array}$ & $\begin{array}{c}\mathrm{e} \\
2.93\end{array}$ & $\begin{array}{l}\text { cde } \\
2.80\end{array}$ \\
\hline & 0.50 & $\begin{array}{l}\text { bcd } \\
3.07\end{array}$ & $\begin{array}{c}\text { de } \\
3.20\end{array}$ & $\begin{array}{c}\mathrm{e} \\
2.60\end{array}$ \\
\hline \multirow{3}{*}{0.10} & 0.00 & $\begin{array}{c}c d \\
2.93\end{array}$ & $\begin{array}{c}d \\
3.33\end{array}$ & $\begin{array}{c}b c \\
3.13 \\
\end{array}$ \\
\hline & 0.10 & $\begin{array}{c}\mathrm{a} \\
3.73\end{array}$ & $\begin{array}{c}\mathrm{a} \\
4.13\end{array}$ & $\begin{array}{c}\mathrm{a} \\
3.80\end{array}$ \\
\hline & 0.50 & $\begin{array}{c}b c \\
3.20\end{array}$ & $\begin{array}{l}a b c \\
3.80\end{array}$ & $\begin{array}{l}\text { bcd } \\
3.00\end{array}$ \\
\hline \multirow{3}{*}{0.50} & 0.00 & $\begin{array}{c}b \\
3.33\end{array}$ & $\begin{array}{c}b c \\
3.73\end{array}$ & $\begin{array}{c}b \\
3.27\end{array}$ \\
\hline & 0.10 & $\begin{array}{c}c d \\
2.93\end{array}$ & $\begin{array}{c}c d \\
3.47\end{array}$ & $\begin{array}{l}\text { bcd } \\
3.00\end{array}$ \\
\hline & 0.50 & $\begin{array}{c}b c \\
3.20\end{array}$ & $\begin{array}{c}a b \\
3.87\end{array}$ & $\begin{array}{c}b \\
2.33\end{array}$ \\
\hline
\end{tabular}


Awad, A. E. et al.

These results agreed with that reported by Soczek and Hempel (1988) who stated that shoots of the cultivars, clementime. saskia and terravise were multiplied on MS media without or with the addition of thiamin, pyridocine, nicotinic acid, myoinositol, tyrosine and adenine sulphate, in the original strength or in concentrations reduced to one-half or one quarter.

C3 - Effect on the combination between thiamine, pyridoxine and nicotinic acid on the growth vigor.

Data in table (16) explain that: no obvious or clear trend can be observed.

Table (16): Effect of combination between thiamine, pyridoxine and nicotinic acid on growth vigor of Cordyline terminals.

\begin{tabular}{|c|c|c|c|c|c|c|c|c|c|c|}
\hline \multicolumn{2}{|c|}{\begin{tabular}{|c|} 
Vitamin \\
Concentration $\mathrm{mg} / \mathrm{L}$
\end{tabular}} & \multicolumn{9}{|c|}{ Nicotinic acid ( $\mathrm{mg} / \mathrm{L}$ ) } \\
\hline \multirow[t]{2}{*}{ Thiamine } & \multirow{2}{*}{ Pyridoxine } & \multicolumn{3}{|c|}{$1^{\text {st }}$ Record } & \multicolumn{3}{|c|}{$2^{\text {nd }}$ Record } & \multicolumn{3}{|c|}{$3^{\text {rd }}$ Record } \\
\hline & & 0.00 & 0.10 & 0.50 & 0.00 & 0.10 & 0.50 & 0.00 & 0.10 & 0.50 \\
\hline \multirow{3}{*}{0.00} & 0.00 & $\begin{array}{c}\mathrm{h} \\
2.00\end{array}$ & $\begin{array}{c}\text { gh } \\
2.20\end{array}$ & $\begin{array}{c}f g \\
2.60\end{array}$ & $\begin{array}{c}\mathrm{i} \\
2.00\end{array}$ & $\begin{array}{c}\mathrm{hi} \\
2.40\end{array}$ & $\begin{array}{r}\text { ghi } \\
2.60\end{array}$ & $\begin{array}{c}c \\
2.00\end{array}$ & $\begin{array}{c}\text { de } \\
2.20\end{array}$ & $\begin{array}{c}\text { de } \\
2.40\end{array}$ \\
\hline & 0.10 & $\begin{array}{c}\text { ef } \\
2.80\end{array}$ & $\begin{array}{c}\mathrm{a} \\
4.00\end{array}$ & $\begin{array}{c}\text { gh } \\
2.20\end{array}$ & \begin{tabular}{|c|} 
ef \\
3.40
\end{tabular} & $\begin{array}{l}\text { bcd } \\
4.20\end{array}$ & $\begin{array}{c}\text { efg } \\
3.20\end{array}$ & $\begin{array}{c}a \\
3.40\end{array}$ & $\begin{array}{c}e \\
4.00\end{array}$ & $\begin{array}{l}\text { cde } \\
3.00\end{array}$ \\
\hline & 0.50 & $\begin{array}{c}\text { ef } \\
2.80\end{array}$ & $\begin{array}{c}\mathrm{h} \\
2.00\end{array}$ & $\begin{array}{c}\mathrm{h} \\
2.20\end{array}$ & \begin{tabular}{|c|} 
def \\
3.60
\end{tabular} & $\begin{array}{r}\text { ghi } \\
2.60\end{array}$ & $\begin{array}{l}\text { fgh } \\
3.00\end{array}$ & $\begin{array}{c}\mathrm{b} \\
3.40\end{array}$ & $\begin{array}{c}e \\
2.20\end{array}$ & $\begin{array}{c}e \\
3.00\end{array}$ \\
\hline \multirow{3}{*}{0.10} & 0.00 & $\begin{array}{l}\text { def } \\
3.00\end{array}$ & $\begin{array}{l}\text { cde } \\
3.20\end{array}$ & $\begin{array}{c}\text { ef } \\
2.80\end{array}$ & $\begin{array}{c}f g h \\
3.00\end{array}$ & \begin{tabular}{|l} 
efg \\
3.20
\end{tabular} & $\begin{array}{c}\text { ef } \\
3.40\end{array}$ & $\begin{array}{c}\mathrm{b} \\
2.60\end{array}$ & $\begin{array}{l}\text { bcd } \\
3.40\end{array}$ & $\begin{array}{c}b c \\
3.20\end{array}$ \\
\hline & 0.10 & $\begin{array}{l}\text { def } \\
3.00\end{array}$ & $\begin{array}{c}\mathrm{a} \\
4.00\end{array}$ & $\begin{array}{l}\mathrm{bcd} \\
3.40\end{array}$ & \begin{tabular}{|c|} 
efg \\
3.20 \\
\end{tabular} & $\begin{array}{c}\mathrm{ab} \\
4.60\end{array}$ & $\begin{array}{l}\mathrm{abc} \\
4.40 \\
\end{array}$ & $\begin{array}{c}\mathrm{a} \\
3.00\end{array}$ & $\begin{array}{c}\mathrm{ab} \\
3.80 \\
\end{array}$ & $\begin{array}{c}\mathrm{a} \\
4.00 \\
\end{array}$ \\
\hline & 0.50 & $\begin{array}{c}\mathrm{a} \\
4.00\end{array}$ & $\begin{array}{c}\text { ef } \\
2.80\end{array}$ & $\begin{array}{l}a b c \\
3.60\end{array}$ & $\begin{array}{c}a b \\
4.60\end{array}$ & $\begin{array}{c}\text { ef } \\
3.40\end{array}$ & $\begin{array}{l}a b c \\
4.40\end{array}$ & $\begin{array}{c}a \\
4.00\end{array}$ & $\begin{array}{c}a \\
3.20\end{array}$ & $\begin{array}{l}\text { bcd } \\
4.20\end{array}$ \\
\hline \multirow{3}{*}{0.50} & 0.00 & $\begin{array}{l}b c d \\
3.40\end{array}$ & $\begin{array}{c}\text { def } \\
3.00\end{array}$ & $\begin{array}{c}a b \\
3.80\end{array}$ & $\begin{array}{c}\mathrm{a} \\
5.00\end{array}$ & $\begin{array}{c}\text { efg } \\
3.20\end{array}$ & $\begin{array}{l}\text { def } \\
3.60\end{array}$ & $\begin{array}{c}\mathrm{b} \\
3.60\end{array}$ & $\begin{array}{l}\text { cde } \\
2.80\end{array}$ & $\begin{array}{c}b \\
2.20\end{array}$ \\
\hline & 0.10 & $\begin{array}{c}\text { def } \\
3.00\end{array}$ & $\begin{array}{l}\text { cde } \\
3.20\end{array}$ & $\begin{array}{c}a \\
4.00\end{array}$ & $\begin{array}{c}\text { ef } \\
3.40\end{array}$ & $\begin{array}{l}\text { def } \\
3.60\end{array}$ & $\begin{array}{l}\text { cde } \\
3.80\end{array}$ & $\begin{array}{c}\mathrm{b} \\
3.00\end{array}$ & $\begin{array}{c}b c \\
3.60\end{array}$ & $\begin{array}{l}\text { bcd } \\
2.00\end{array}$ \\
\hline & 0.50 & $\begin{array}{l}\text { cde } \\
3.20\end{array}$ & $\begin{array}{c}\mathrm{a} \\
4.00\end{array}$ & $\begin{array}{c}\mathrm{ab} \\
3.80\end{array}$ & $\begin{array}{c}\text { fgh } \\
3.00\end{array}$ & $\begin{array}{l}a b c \\
4.40\end{array}$ & $\begin{array}{l}\text { bcd } \\
4.20\end{array}$ & $\begin{array}{c}\mathrm{b} \\
2.40\end{array}$ & $\begin{array}{c}f \\
3.60\end{array}$ & $\begin{array}{c}\mathrm{b} \\
2.80\end{array}$ \\
\hline
\end{tabular}

\section{REFERENCES}

Alka N.; S. Kumal; K. Bansal and P.S Srivastava (2003): In vitro micropropagation, differntiation of aerial bulbils and tubers and diosgenin content in Dioscorea bulbifera. Planta Medica, 69 (8): 778779.

Awad, A. E.; K. A. Dawah, H. A. Emara, and M. S. El- Shaer (2008): Medium constituents as affecting the growth of Cordyline terminalis cv.Atoom in vitro. J. Agric. Sci. Mansoura Univ., 33 (3): 1921 - 1934, 2008. 
Beruto, M.; P. Curir; G. B. Lercari and R. Giusta (1983): The in vitro propagation of Cordyline terminals L. Cv. Calypso. Annali,, dell.Istituto, Sperimentale per la Floriculture., 14: 1, 37-46.

Curir, P.; B. Ruffoni; F. Massabo; and F. Damiano (1990): Induction of somatic embryogenesis in Genista monosperma lam. Acta Horticulturae., 280: 113-116.

Ghosh, B. and S. Sen (1994): Effect of explant, light intensity and grouth regulator on stable regeneration of Asparagus plumosus Baker. Nucleus Calcutta., 37 (1/2) : 24-29.

Gomez, K. A. and A. A. Gomez (1984): Statistical Procedures for the Agricultural Researches. John Wiley and Son, Inc. New York.

Kamada, H. and H. Harada (1979): Influence of several growth regulators and amino acids on in vitro organogenesis of Torenia fournieri Lind., Journal of Experimental Botany., 30 (114): 36-37.

Khosh, K. M.; A. Shekafandeh and H. Azarabhsh (1984): Micropropagation of myrtle. Scientia Horticulture, 22 (211): 139-146.

Kunisaki, J. T. (1989): In vitro propagation of leucospermum hybrid, Hawaii Gold. HortScience., 24 (4): 686-687.

Le, C. L. (1980): Micropropagation in vitro of Aeschynanthus hildebrandii. Revue Suisse de Viticulture d Arboriculture et d Horticulture., 12 (5): 245-248.

Razdan, M. K. (1993): An introduction to plant tissue culture. Dep. of Botany, Ramjas College, (Univ. of Delhi) University Enclave. Oxford and IBH Publishing Co. PTV. LTD. New Delhi, Bombay, Calvutta.

Sharma D. R.; S. Dawra and J. B. Chowdhury (1984): Somatic embryogenesis and plant regeneration in date plam (Phoenix dactylifera linn.) cv. Khadravi through tissue culture. Indian Journal of Experimental Biology., 22 (11): 596-598.

Soczek, U. and M. Hemple (1988): The influence of some organic medium compounds on multiplication of gerbera in vitro., Acta Horticulturae., 226, vol П: 643-646.

Thiruvengadam, M.; S. V. Mohamed; C. H. Yang and N. Jayabalan (2006): Development of an embryogenic suspension culture of bitter melon (Momordica charantia L.). Scientia Horticulturae., 109 (2): 123-129.

Wang, S. O. and S. S. Ma (1978): Clonal multiphlication of chrysanthemum in vitro. Journal of the Agriculture Association of China., (c1): 63-73. 
Awad, A. E. et al.

\section{تأثير مكونات البيئة على نمو نبات الكلورديلين معملياً:

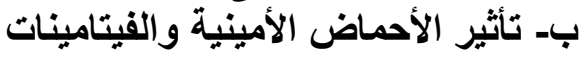

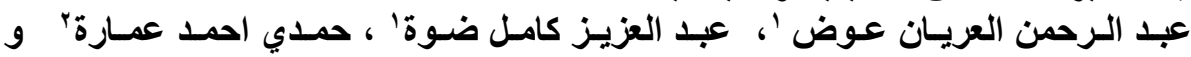

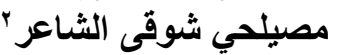

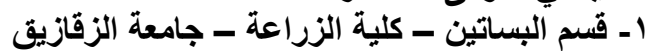 r ـ قسم بيوتكنولوجيا النبات ـ معهل الهندسة الوراثية والتكنولوجيا الحيوية ـ جامعة المنوفية}

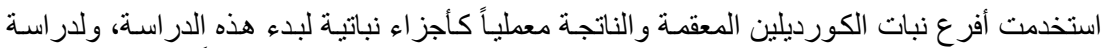

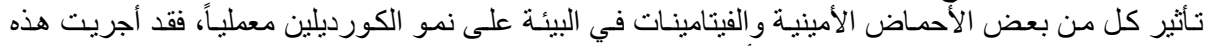

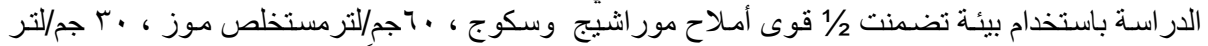

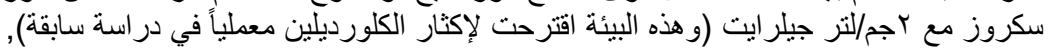

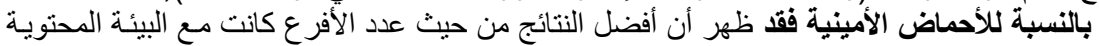

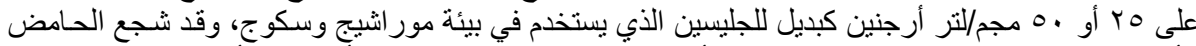

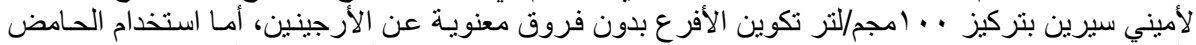

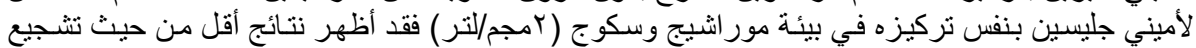

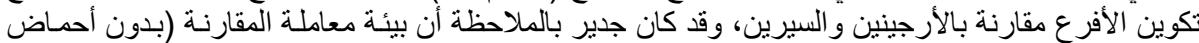

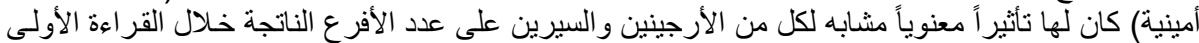

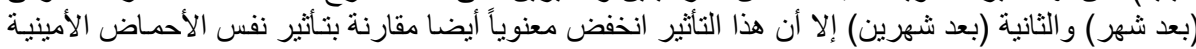

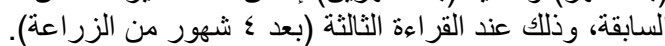

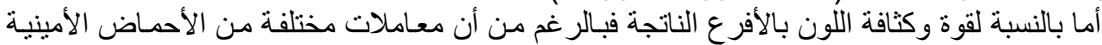

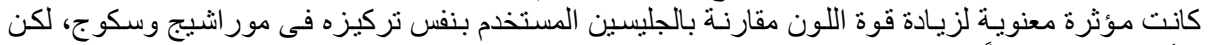

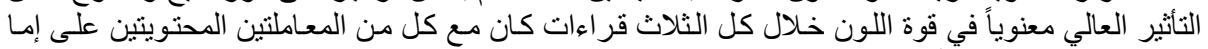

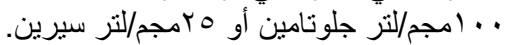

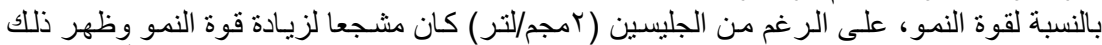

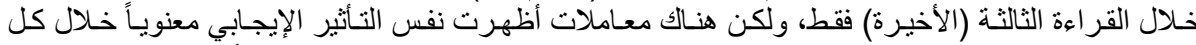

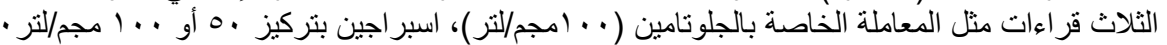

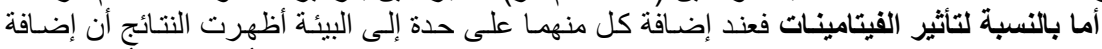

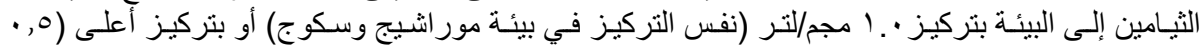

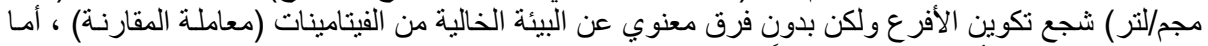

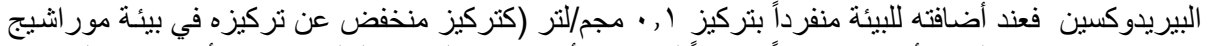

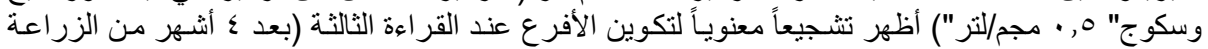

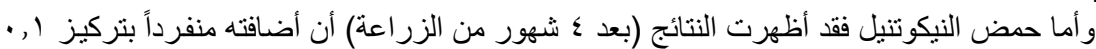

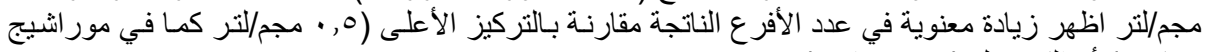
وسكوج) أو الكنترول (بدون فيتامين).

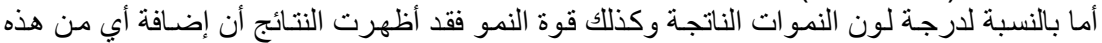

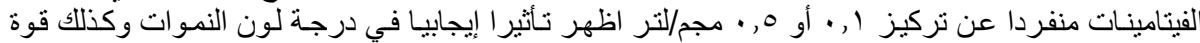

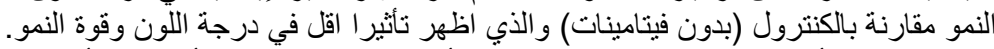

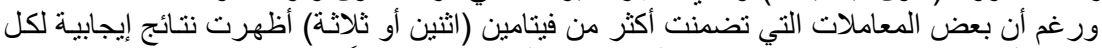

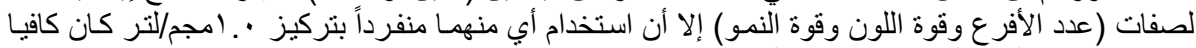

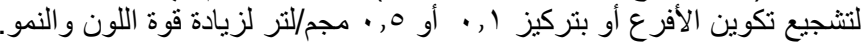


J. Agric. Sci. Mansoura Univ., 33 (3), March, 2008

2199

2200

2201

2202

2203

2204

2205

2206

2207

2208

2209

2210

2211

2212

2213

2214

2215

2216 